\title{
SLY regulates genes involved in chromatin remodeling and interacts with TBL1XR1 during sperm differentiation
}

\author{
Charlotte Moretti ${ }^{1,2,3,8}$, Maria-Elisabetta Serrentino ${ }^{1,2,3,8}$, Côme laly-Radio ${ }^{1,2,3}$, Marion Delessard ${ }^{1,2,3}$, Tatiana A Soboleva ${ }^{4}$, \\ Frederic Tores ${ }^{5}$, Marjorie Leduc ${ }^{6}$, Patrick Nitschké ${ }^{5}$, Joel R Drevet ${ }^{7}$, David J Tremethick ${ }^{4}$, Daniel Vaiman ${ }^{1,2,3}$, Ayhan Kocer ${ }^{7}$ and \\ Julie Cocquet, ${ }^{*, 1,2,3}$
}

Sperm differentiation requires unique transcriptional regulation and chromatin remodeling after meiosis to ensure proper compaction and protection of the paternal genome. Abnormal sperm chromatin remodeling can induce sperm DNA damage, embryo lethality and male infertility, yet, little is known about the factors which regulate this process. Deficiency in Sly, a mouse Y chromosome-encoded gene expressed only in postmeiotic male germ cells, has been shown to result in the deregulation of hundreds of sex chromosome-encoded genes associated with multiple sperm differentiation defects and subsequent male infertility. The underlying mechanism remained, to date, unknown. Here, we show that SLY binds to the promoter of sex chromosome-encoded and autosomal genes highly expressed postmeiotically and involved in chromatin regulation. Specifically, we demonstrate that Sly knockdown directly induces the deregulation of sex chromosome-encoded H2A variants and of the H3K79 methyltransferase DOT1L. The modifications prompted by loss of Sly alter the postmeiotic chromatin structure and ultimately result in abnormal sperm chromatin remodeling with negative consequences on the sperm genome integrity. Altogether our results show that SLY is a regulator of sperm chromatin remodeling. Finally we identified that SMRT/N-CoR repressor complex is involved in gene regulation during sperm differentiation since members of this complex, in particular TBL1XR1, interact with SLY in postmeiotic male germ cells.

Cell Death and Differentiation (2017) 24, 1029-1044; doi:10.1038/cdd.2017.32; published online 5 May 2017

The postmeiotic phase of spermatogenesis is a fascinating process in terms of transcriptional regulation and chromatin re-organization. Indeed, after meiosis, during which the genetic material is recombined and then partitioned in haploid cells, round spermatids experience a differentiation program characterized by profound morphological changes: elongation, nucleus condensation and acquisition of new structures such as the acrosome and the flagellum. In many organisms including mammals, this process involves transcriptional regulation by master genes, and expression of thousands of genes in round and early elongating spermatids, before the spermatid chromatin is compacted and transcription is progressively shut down. $^{1-6}$

Chromatin compaction is achieved by a transition from a nucleosome-based organization to a unique genomepackaging structure based on non-histone proteins, called protamines. The replacement of histones by protamines starts with incorporation of spermatid-enriched histone variants and post translational modifications of histone residues, the most predominant of which is histone $\mathrm{H} 4$ hyperacetylation. These steps are thought to open the chromatin to facilitate the action of topoisomerases and the removal of histones; then, transition proteins are incorporated and finally replaced by protamines (for review, see ${ }^{7}$ ). In mice, haploinsufficiency of genes coding for protamines (i.e., Prm1 or Prm2) is sufficient to result in male infertility and leads to sperm DNA damage and embryo lethality; ${ }^{8,9}$ protamines are therefore essential to mammalian fertility with a function in compaction, as well as protection of the paternal genome until after fertilization. Little is known about the factors and molecular mechanisms which regulate chromatin remodeling during sperm differentiation. Studies of mouse genetic models have identified a few nuclear factors, histone variants and chromatin remodelers required for histone-to-protamine transition, such as BRDT (Bromodomain testis specific) protein, ${ }^{10}$ histone $\mathrm{H} 2 \mathrm{~B}$ variant $\mathrm{TH} 2 \mathrm{~B},{ }^{11}$ and the chromodomain helicase DNA-binding protein $5 .{ }^{12}$

We and others have also shown that the mouse $Y$ chromosome long arm (MSYq) encodes genetic information required for normal chromatin compaction during sperm differentiation: males with deletions of MSYq have severe sperm differentiation defects and produce deformed spermatozoa with poorly compacted chromatin, which are unable to

\footnotetext{
${ }^{1}$ Department of Development, Reproduction and Cancer, INSERM, U1016, Institut Cochin, Paris, France; ${ }^{2}$ CNRS, UMR8104, Paris, France; ${ }^{3}$ Université Paris Descartes, Sorbonne Paris Cité, Faculté de Médecine, Paris, France; ${ }^{4}$ The John Curtin School of Medical Research, The Australian National University, PO Box 334, Canberra, ACT 2601, Australia; ${ }^{5}$ Bioinformatics facility, Université Paris Descartes, Sorbonne Paris Cité, Institut Imagine, Paris, France; ${ }^{6} 3 \mathrm{P} 5$ proteomic facility, Institut Cochin, Université Paris Descartes, Sorbonne Paris Cité, Paris, France and ${ }^{7}$ Genetic Reproduction and Development, CNRS UMR6293 - INSERM U1103 - Clermont Université, 63178 Aubière Cedex, France

*Corresponding author: J Cocquet, Development, Reproduction, Cancer, Institut Cochin - Inserm u1016 - Université, 24 rue du Faubourg St Jacques, PARIS 75014, France. Tel: +33144412319; Fax: +33144412302; E-mail: julie.cocquet@ inserm.fr

${ }^{8}$ These authors contributed equally to this work.

Received 20.9.16; revised 25.1.17; accepted 09.2.17; Edited by P Salomoni; published online 05.5.2017
} 
fertilize oocytes in vivo and in vitro. ${ }^{13}$ Sly, a multicopy gene of MSYq only expressed in postmeiotic cells, ${ }^{14,15}$ largely contributes to these phenotypes since males with Sly specifically

a
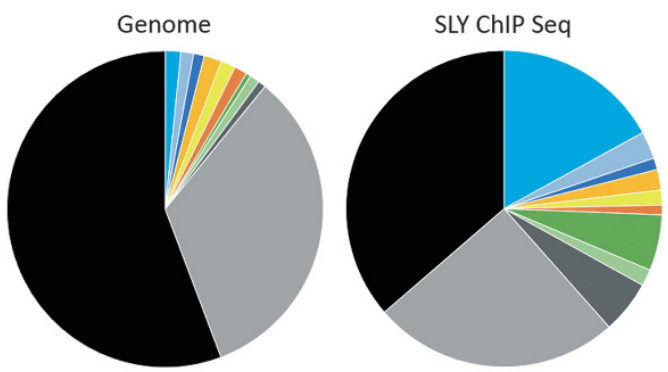

- Promoter ( $<=1000 \mathrm{bp})$ = Downstream $(<=1000 \mathrm{bp})$ - 5 'UTR = Intron

C SLY ChIP-qPCR

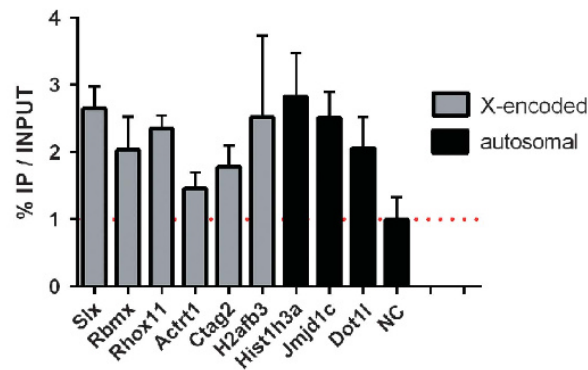

e Percentage of expressed vs. not expressed genes

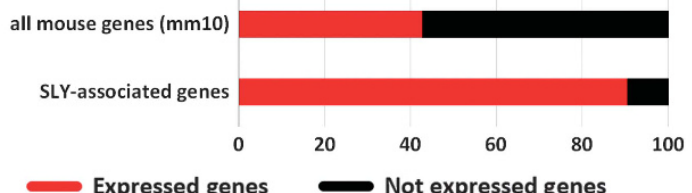

g Comparison of SLY ChIP-Seq with other ChIP-Seq

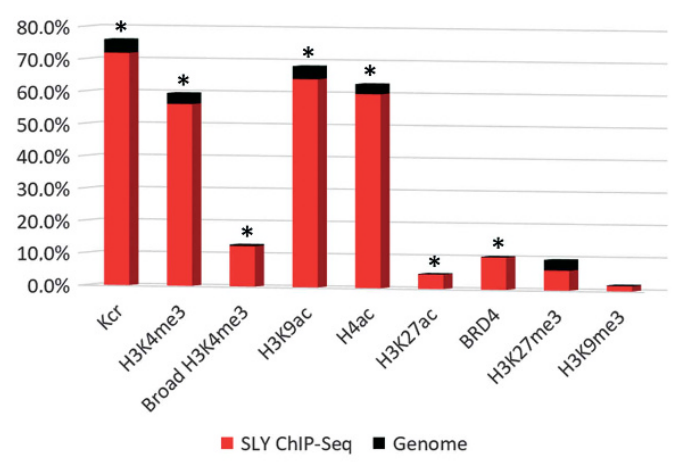

knocked down (Sly-KD males) also present abnormal sperm differentiation, including abnormal chromatin compaction and increased sperm DNA damage. ${ }^{15,16}$ It has been shown that

b

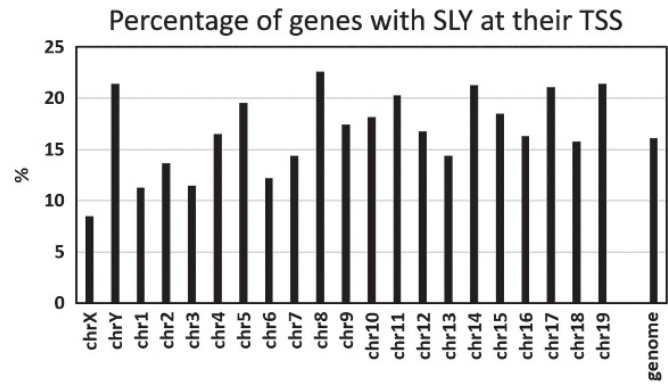

d

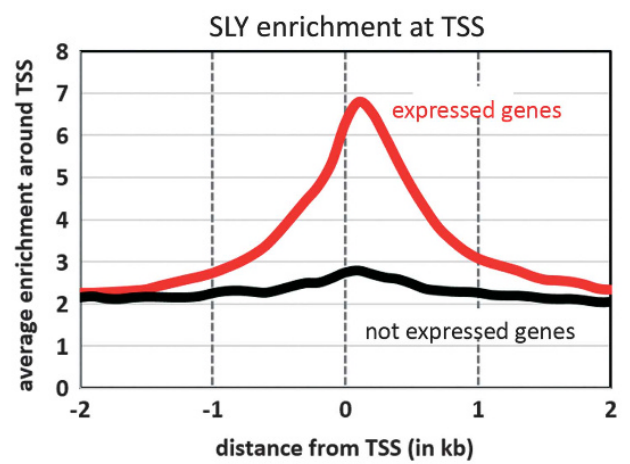

f

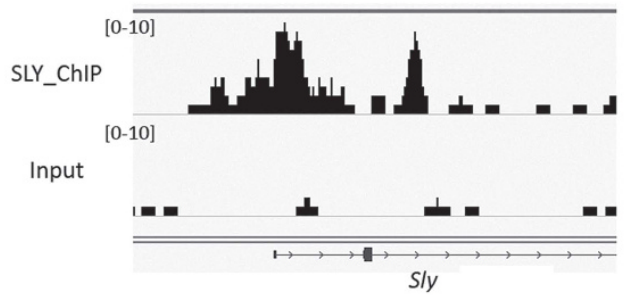

h

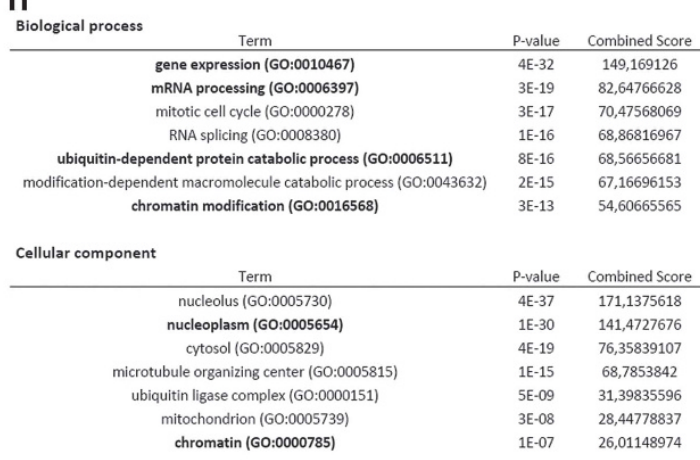

Molecular function

\begin{tabular}{ccc} 
Term & P-value & Combined Score \\
\hline ligase activity (GO:0016874) & $4 \mathrm{E}-10$ & 37,39887631 \\
ATP binding (GO:0005524) & $1 \mathrm{E}-09$ & 35,31143413 \\
transcription coactivator activity (GO:0003713) & $2 \mathrm{E}-08$ & 29,99233107 \\
mRNA binding (GO:0003729) & $2 \mathrm{E}-07$ & 23,06863137 \\
chromatin binding (GO:0003682) & $2 \mathrm{E}-06$ & 20,28180813 \\
structural constituent of ribosome (GO:0003735) & $9 \mathrm{E}-07$ & 20,17309317 \\
protein serine/threonine kinase activity (GO:0004674) & $3 \mathrm{E}-06$ & 19,76800778
\end{tabular}


Sly knockdown leads to the upregulation of $\sim 100$ sex chromosome-encoded genes in round spermatids. At the protein level, SLY lacks any conserved domain except for a COR1 region identified in SYCP3, a protein involved in the meiotic synaptonemal complex. ${ }^{14,17}$ Therefore, the mechanism by which SLY controls gene expression and the origin of the sperm differentiation defects observed in its absence remain unclear.

In the present study, we investigated the molecular function of SLY by performing chromatin immunoprecipitation followed by high-throughput sequencing (ChIP-Seq) and by coimmunoprecipitation followed by mass spectrometry. We discovered that SLY associates with the transcriptional start sites of thousands of genes expressed postmeiotically, many of which are involved in gene regulation or chromatin remodeling. We focused on SLY-target genes relevant to the

Table 1 SLY ChIP-Seq details

\begin{tabular}{lcc}
\hline & SLY ChIP DNA & Input DNA \\
\hline Total number of reads & 37495530 & 26337788 \\
Total number of alignments & 23699247 & 25636677 \\
Final number of tags (no duplicate & 9754313 & 20829154 \\
reads) & 9754313 & 754313 \\
Normalized & MACS 1.4.2 & \\
& peak calling & \\
& 3631 & \\
\hline Paired peaks & 147 & \\
Predicted fragment length & 13664 & \\
Final MACS peaks & 99 & \\
Negative peaks & $0.72 \%$ & \\
False discovery rate & Annotation & \\
& 13664 \\
\hline $\begin{array}{l}\text { SLY-enriched genomic regions } \\
\text { Percentage of intervals within }\end{array}$ & $67.8 \%$ \\
10Kb of NCBI genes (mm10) & $46.8 \%$ \\
$\begin{array}{l}\text { Percentage of Intervals within } \\
\text { Promoter Region (-7500/ } \\
\text { +2500 bp of NCBI Gene Start) }\end{array}$ & \\
$\begin{array}{l}\text { Percentage of NCBI genes } \\
\text { (mm10) with SLY at TSS }\end{array}$ & $16 \%$ \\
Percentage of NCBI genes \\
(mm10) with SLY at $\pm 1 \mathrm{~kb}$ of TSS
\end{tabular}

chromatin defects observed in Sly-deficient sperm, and found that SLY controls the expression of genes coding for spermatid-specific histone variants and for chromatin regulators such as the H3K79 methyltransferase, DOT1L. Overall, we show that Sly deficiency leads to changes in the chromatin composition just prior to histone removal, which impact on histone-to-protamine exchanges and, ultimately, on sperm atozoa chromatin content and function, as well as on their genome integrity. Finally, we found that SLY is part of the SMRT/N-CoR complex and interacts with TBL1XR1.

Altogether our data identify for the first time the molecular role of SLY and link the sperm chromatin compaction phenotype observed in Sly-deficient males to molecular pathways important for chromatin remodeling during sperm differentiation, in particular, the regulation of $\mathrm{H} 3 \mathrm{~K} 79$ methylation.

\section{Results}

SLY marks the sperm differentiation genetic program. To investigate the molecular mechanism by which SLY controls postmeiotic gene expression, we performed ChIP-Seq analyses on purified round spermatids from wild-type (WT) males with anti-SLY antibody. We found that SLY protein preferentially binds to the start of genes, in the $1 \mathrm{~kb}$ region surrounding the transcription start site (TSS) and, overall, occupies the TSS of $\sim 16 \%$ of mouse genes $(6,381$ genes with SLY at TSS, 7,280 genes with SLY at $\pm 1 \mathrm{~kb}$ of TSS) (Figure 1a, Supplementary Figure $1 \mathrm{~A}$ and Table 1). No particular bias towards the sex chromosomes was observed (Figure 1b and Supplementary Figure 1B). ChIP followed by real-time PCR (ChIP-qPCR) confirmed the ChIP-Seq results (Figure 1c). Strikingly, comparison with published RNAseq data $^{6,18}$ showed a strong correlation between SLY-genomic targets and genes expressed in round spermatids ( $89 \%$ versus $41 \%$ of all mouse genes, $X^{2}, P<0.0001$; Figures $1 \mathrm{~d}$ and $\mathrm{e})$, and more specifically with a high expression level (91\% of SLY-associated genes are among the 50\% most expressed genes, $X^{2}, P<0.0001 ; 36 \%$ among the $10 \%$ most expressed genes, $\left.X^{2}, P<0.0001\right)$. Interestingly, SLY was found to bind to the TSS of master genes of spermatid transcriptional regulation such as Crem, Creb1, Crebbp, Kif17, Taf7l, Terf2, Tbpl1, Papolb, Piwil1 or Brd4. ${ }^{1,2,19}$ SLY presence appears as an excellent marker of genes essential

Figure 1 SLY marks the sperm differentiation program and co-localizes with active epigenetic marks. (a) Annotation of SLY-enriched genomic regions (right) compared to whole genome (left), using Cis-regulatory Element Annotation System (CEAS). (b) Graphic representation of the percentage of genes found occupied by SLY protein by ChIP-Seq on each chromosome. (c) Validation of SLY-target genes by ChIP-qPCR on round spermatids using antibody against SLY. The TSS of SIx, Rbmx, Rhox11, Actrt1, Ctag2 and Hist1h3a were found enriched in SLY by ChIP-Seq (present study) and were previously found deregulated in Sly-KD versus WT samples by micro-array and/or RT-qPCR analyses. ${ }^{15}$ The TSS of H2afb3, Jmjd1c and Dot1/ were found enriched in SLY by ChIP-Seq (present study) and were found deregulated in Sly-KD versus WT round spermatids by RT-qPCR (present study, cf. Figure 2b). Sex chromosome-encoded genes are represented in black and autosomal genes, in gray. The Y-axis represents the mean enrichment (\% IP/input) \pm S.E.M. normalized to a negative control region (NC) located at $\sim 170 \mathrm{~kb}$ from a TSS. All regions shown were found significantly enriched in SLY compared to the negative control region (t-test, $P<0.05 ; n=3-6$ samples). (d) Graphic representation of SLY ChIP-Seq profile showing the average enrichment of SLY around the TSS of genes expressed (in red) and not expressed (in black) in round spermatids. (e) Graphic representation of the percentage of genes that are expressed (in red) and not expressed (in black) in round spermatids, among all mouse genes (mm10 genome version) or among SLY-associated genes. SLY is significantly enriched at the start (i.e., TSS $\pm 1 \mathrm{~kb}$ ) of genes expressed in round spermatids $\left(\chi^{2}, P<0.0001\right)$. (f) Representation of SLY ChIP-Seq and input profiles at Sly gene locus. (g) Graphic representation of the comparison between SLY ChIP-Seq data set and ChIP-Seq data sets from chromatin marks (Kcr, H3K4me3, H3K9ac, H4ac, H3K27ac, H3K27me3, H3K9me3) and from BRD4, in round spermatids. In red is represented the percentage of SLY-enriched genomic regions which overlaps with that of the chromatin mark-ffactor-enriched genomic regions; in black is represented the percentage of the genome covered by the chromatin mark/factor. A star indicates a significant enrichment at SLY-covered regions compared to global genomic coverage $\left(\chi^{2}, P<0.03\right)$. (h) Table recapitulating the results of gene ontology analyses of SLY ChIP-Seq genes using EnrichR. See also Supplementary Figure $1 \mathrm{C}$ 


\begin{tabular}{|c|c|c|c|c|c|}
\hline & \multirow[b]{2}{*}{$\begin{array}{l}\text { Total Nb } \\
\text { of genes }\end{array}$} & \multicolumn{2}{|c|}{$\begin{array}{l}\text { Nb of upregulated genes in } \\
\text { Sly-KD round spermatids }\end{array}$} & \multicolumn{2}{|c|}{$\begin{array}{l}\text { Nb of downregulated genes } \\
\text { in Sly-KD round spermatids }\end{array}$} \\
\hline & & $X Y(\%)$ & Autosomal (\%) & $X Y(\%)$ & Autosomal (\%) \\
\hline Minimal list $>1.5 \times$ deregulation & 413 & $276(66,8 \%)$ & $96(23,2 \%)$ & $0(0 \%)$ & $41(10 \%)$ \\
\hline List extended to close paralogs $>1.5 \times$ deregulation & 752 & $465(61,8 \%)$ & $232(30,9 \%)$ & $0(0 \%)$ & $55(7,3 \%)$ \\
\hline All deregulated genes $(P<0.05)$ & 1171 & $433(37 \%)$ & $353(30 \%)$ & $0(0 \%)$ & $385(33 \%)$ \\
\hline
\end{tabular}

to the spermatid differentiation program. This was confirmed by gene ontology analyses in which one of the most significant hits was 'spermatids' (Supplementary Figure 1C). Of note, Sly promoter itself is occupied by SLY protein (Figure 1f).

Next, we compared SLY ChIP-Seq with published ChIP-Seq of chromatin marks performed in round spermatids. ${ }^{19-22}$ SLY profile was found to be very similar to that of active marks (Figure 1g,Supplementary Figure 2A), i.e., chromatin marks associated with the promoter of expressed genes, ${ }^{19,21,23,24}$ such as H3K4me3 (trimethylation of histone $\mathrm{H} 3$ lysine 4), $\mathrm{Kcr}$ (histone lysine crotonylation), H3K9ac (acetylation of histone $\mathrm{H} 3$ lysine 9), H3K27ac (acetylation of histone H3 lysine 27) and $\mathrm{H} 4 \mathrm{ac}$ (acetylation of histone $\mathrm{H} 4$ ). Interestingly, the overlap of SLY with active marks is not restricted to gene TSS and proximal promoters. Indeed, approximately half of SLYgenomic targets are located at gene TSS and proximal promoters (Table 1) while $\sim 2 / 3$ rd of SLY-genomic targets correlate with $\mathrm{Kcr}$ and H3K9ac (Figure 1g). This suggests that SLY overlaps with active marks not only at gene TSS/proximal promoter but also at distal promoters and enhancer regions, since active chromatin marks are known to be enriched in these regions. SLY also correlates with BRD4 genomic localization, which has been shown to be enriched at spermatogenesis-specific genes. ${ }^{19}$ On the other hand, it differed significantly from chromatin marks associated with transcriptional repression such as the repressive marks H3K27me3 (trimethylation of histone H3 lysine 27) and H3K9me3 (trimethylation of histone H3 lysine 9) (Figure 1g, Supplementary Figure 2A). Benayoun et al. have described that broad $\mathrm{H} 3 \mathrm{~K} 4 \mathrm{me} 3$ regions correlate with a specific cell identity. ${ }^{25}$ Here, of the broadest H3K4me3 domains of round spermatids, $74 \%$ intersect with SLY domains, confirming that SLY is a good marker of sperm differentiation program/ spermatid identity (Figure 1g).

SLY controls the expression of genes involved in transcriptional regulation, chromatin remodeling and the ubiquitin pathway. Gene ontology analyses for molecular and biological functions of the list of 7280 SLY-bound genes identified by ChIP-Seq revealed a clear enrichment for genes encoding nuclear proteins involved in the regulation of gene expression, chromatin binding, ubiquitin ligase activity, stress, genomic/chromosomal instability and DNA repair pathway (Figure 1h, Supplementary Figure 1C).

To compare SLY ChIP-Seq gene list with the list of genes deregulated in Sly-deficient round spermatids (Sly-KD), we first re-analyzed our previously published microarray data ${ }^{15}$ using the most recent version of the mouse genome (GRCm38/ $\mathrm{mm10}$ ) since it is more complete in term of sequence length and annotation, especially of the $\mathrm{Y}$ chromosome, than the previous version GRCm37/mm9 (i.e., in $\mathrm{mm} 9$ version, only $15 \%$ of the $Y$ chromosome was assembled). Over 400 genes were found deregulated more than 1.5 -fold $(P<0.05)$, a majority of which are encoded by the sex chromosomes, in agreement with our previous observations. ${ }^{15}$ Since many of those genes are present in multiple copies, we included closely related paralogous genes and obtained a total of 752 deregulated genes, again with a strong bias towards X- and Y- encoded upregulated genes (Table 2). Comparison with SLY-associated genes (i.e., the 7280 SLY ChIP-Seq genes) showed a higher proportion of upregulated genes versus downregulated genes $\left(x^{2}, P=0.005\right)$ (Table 2, Supplementary Figure 2B). When including all 1171 significantly deregulated genes (no threshold, $P<0.05$ ), a higher proportion of autosomal upregulated and downregulated genes was found and, this time, there were more downregulated than upregulated genes among the genes enriched in SLY at their TSS $\left(x^{2}, P=0.012\right)$ (Table 2, Supplementary Figure 2B).

Next, we investigated why some autosomal genes had SLY at their TSS and yet were not found deregulated in Sly-KD round spermatids by microarray. Since real-time PCR is a more sensitive technique than expression microarrays, ${ }^{26}$ we re-examined by quantitative real-time PCR (RT-qPCR) the expression level of those autosomal genes, focusing on those with the highest SLY enrichment at their gene start (10\% of genes with highest SLY peak, Supplementary Figure 3). In this gene list are several members of the Speer gene cluster, multicopy genes of chromosome 14 with yet unknown functions and, interestingly, genes encoding proteins with a known role in chromatin regulation, such as Dot1/ which encodes an H3K79 methyltransferase (Figure 2a, Supplementary Figure 3). By RTqPCR we found several of those autosomal genes significantly deregulated (up or downregulated) in Sly-KD spermatids compared to WT spermatids (Figure 2b). With the same approach, we identified additional sex chromosome-encoded genes significantly upregulated in Sly-KD spermatids such as Spin2d, Gmcl11, Ube2a, Kdm5c and genes encoding spermatid-specific histone variants, such as H2afb3, H2al1 (aka 1700012L04Rik) or H1fnt (Figures $2 \mathrm{~b}$ and c). ${ }^{7,27-30}$ Their closely related paralog $\mathrm{H} 2 \mathrm{afb} 1$ encoded by an autosome, is not regulated by SLY (Figures $2 b$ and $c$ ). Since Sly knockdown leads to increased transcription of $H 2 a f b 3$, we checked whether it affects $\mathrm{H} 2 \mathrm{~A} . \mathrm{B} 3$ incorporation in the spermatid chromatin by ChIP-qPCR and found that H2A.B3 level is higher at the TSS of 
a

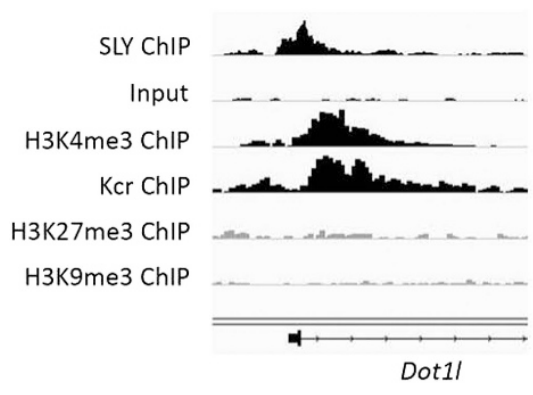

b

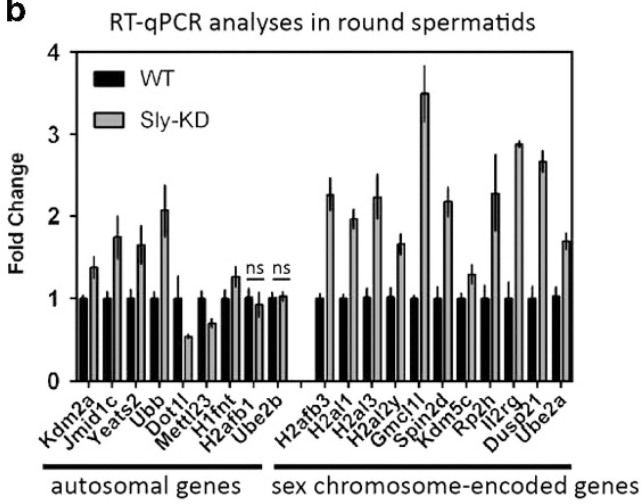

C
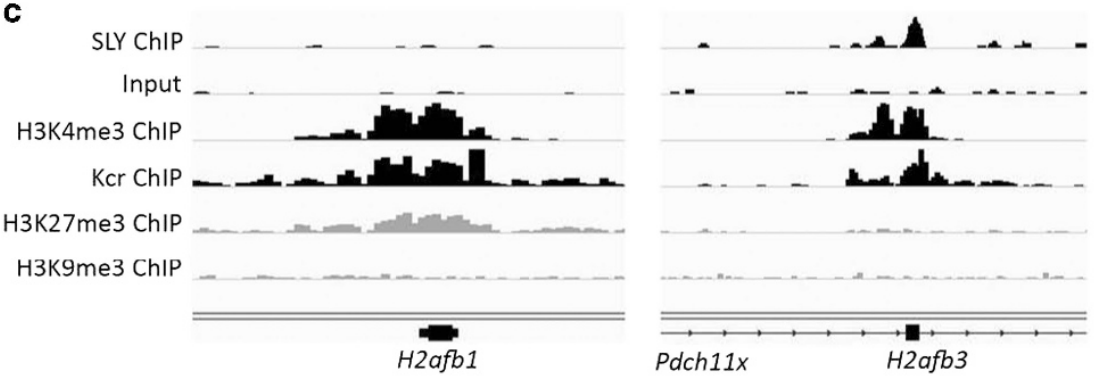

d

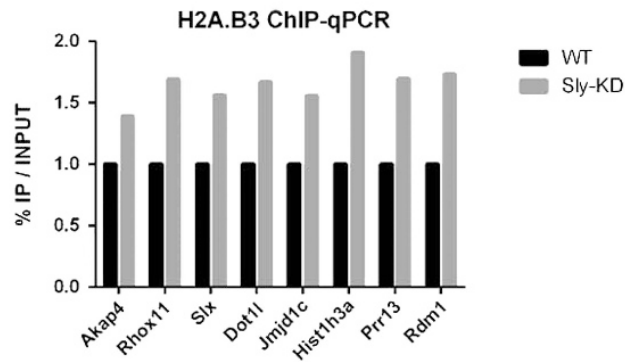

Figure 2 SLY controls the expression of genes involved in chromatin regulation during postmeiotic sperm differentiation. (a) Representation of SLY ChIP-Seq, its input, H3K4me3 ChIP-Seq, Kcr ChIP-Seq, H3K27me3 ChIP-Seq and H3K9me3 ChIP-seq at the TSS of Dot1I, one of the genes found to have the highest enrichment of SLY by ChIPSeq. (b) Transcript level of autosomal genes found to be highly enriched in SLY protein at their TSS (10\% of genes with highest SLY peak, Supplementary Figure 3) and of XYencoded genes, measured by RT-qPCR in Sly-KD and WT round spermatids. The graph represents the geometric mean \pm S.E.M (after normalization with $\beta$-actin, $n=3-6$ samples per genotype). For all except two genes (labeled with 'ns' for non-significant), a significant difference between Sly-KD and WT samples was found with a $P$-value $<0.05$ (t-test). (c) Representation of SLY ChIP-Seq, its input, H3K4me3 ChIP-Seq, Kcr ChIP-Seq, H3K27me3 ChIP-Seq and H3K9me3 ChIP-seq. SLY co-localizes with active epigenetic marks H3K4me3 and Kcr at the TSS of H2afb3 (located in an intron of Pdch11x) but not of its autosomal-encoded homolog, H2afb1. (d) ChIP-qPCR experiments on WT and Sly-KD round spermatids using antibody against H2A.B3. The TSS of expressed genes was found enriched in H2A.B3 in Sly-KD compared to WT round spermatids ( $n=3$ samples per genotype). The $Y$-axis represents the mean enrichment (\%IP/input) normalized to the corresponding WT value. A significant increase in H2A.B3 level at the TSS was found in Sly-KD compared to WT samples when considering all tested genes $(t$-test, $P<0.05)$

expressed genes in Sly-KD compared to WT round spermatids (Figure 2d).

Overall our data show that, when considering genes expressed in spermatids, all sex chromosome-encoded genes are upregulated in Sly-KD spermatids while autosomal genes are either upregulated, downregulated or unchanged.

Sly-dependent deregulation of the H3K79 histone methyltransferase DOT1L impairs H3K79 methylation prior to histone-to-protamine exchange. One of the genes with highest enrichment of SLY at its start is Dot1l (Figure 2a) which encodes the only known H3K79 histone methyltransferase. It is presumed to be important for chromatin remodeling during sperm differentiation, because high levels of H3K79 methylation precede histone removal during spermatid elongation. ${ }^{31,32}$ Besides, analyses of published RNASeq and microarray data show that Dot $1 /$ is particularly expressed after meiosis in mice (Figure $3 a$ ) and humans (Figure 3b). Immunofluorescence experiments on WT mouse testicular samples show that DOT1L protein is enriched at the sex chromatin in round spermatids and appears as nuclear punctuated signals in step 9-11 elongating spermatids (Figure 3c, Supplementary Figure 4). High H3K79 dimethylation (H3K79me2) levels were also observed in round spermatids and at the onset of spermatid elongation (step 10-12 elongating spermatids, Supplementary Figure 6) just prior to histone-to-protamine exchange, as described by Dottermusch-Heidel et al. ${ }^{31,32}$ Since Dot1/ is downregulated 
a

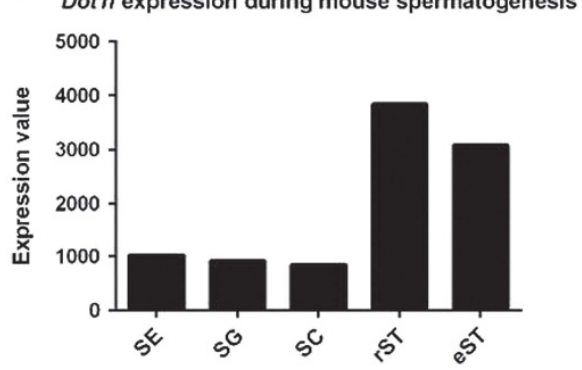

b $_{\text {DOT1L expression during human spermatogenesis }}$

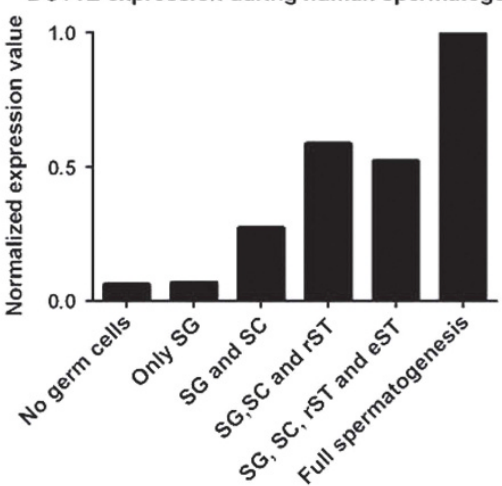

c
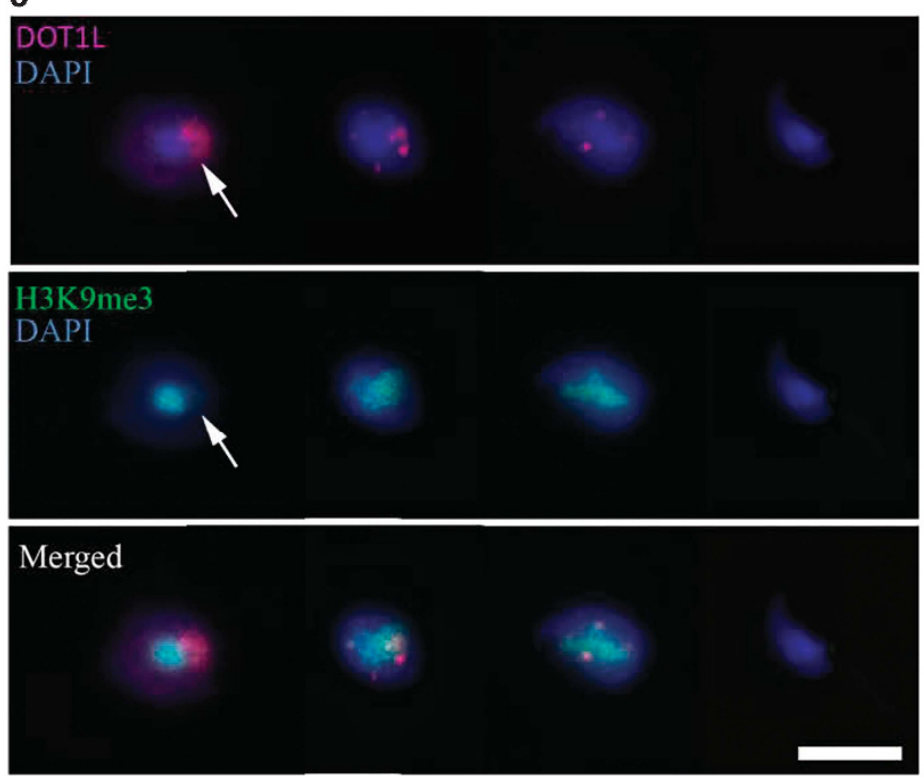

Figure 3 DOT1L is highly expressed in postmeiotic germ cells. (a) Schematic of Dot1/ expression as found by RNA-Seq on Sertoli cells (SE) and mouse purified germ cells fractions (SG: spermatogonia; SC: spermatocytes; rST: round spermatids; eST: elongating spermatids) (analysis of GSE $3500{ }^{18}{ }^{18}$ ). (b) Schematic diagram of DOT1L expression in humans as found by micro-array analyses of testicular biopsies with different germ cell contents (SG, SC, rST, eST) (analysis of Affymetrix HG-U133_Plus_2 probe no. 231297_at $\left.{ }^{61}\right)$. (c) Immunofluorescence detection of DOT1L protein (red) in germ cells at 4 stages of postmeiotic differentiation (from left to right: round spermatid, early elongating spermatid, late elongating spermatid, spermatozoa). DAPI (blue) was used to stain nuclei. H3K9me3 (in green) marks the chromocenter (i.e., the constitutive pericentromeric heterochromatin) and the $X$ or $Y$ chromosome (i.e., the postmeiotic sex chromatin, PMSC, indicated by an arrow). ${ }^{71}$ Scale bar indicates $10 \mu \mathrm{m}$. See also Supplementary Figure 4

in Sly-KD spermatids (Figure 2b, Supplementary Figure 5), we looked at H3K79me2 expression: by immunofluorescence, there was a notable decrease in H3K79me2 levels in step 10-12 elongating spermatids from Sly-KD males compared to WT elongating spermatids (Figures $4 \mathrm{a}, \mathrm{b}$ and Supplementary Figure 6). We next purified elongating/ condensing spermatid fractions from WT and Sly-KD testes by elutriation. ${ }^{33}$ Despite an elevated intra-genotype variability we did not observe major differences in the proportion of elongating/condensing spermatids between WT and Sly-KD fractions; those fractions can therefore be compared. We quantified H3K79me2 levels by ChIP-qPCR and western blot and confirmed that $\mathrm{H} 3 \mathrm{~K} 79 \mathrm{me} 2$ is reduced in Sly-KD compared to WT elongating/condensing spermatids (Figure 4c, Supplementary Figure 7A and C). Finally, we observed by immunofluorescence that H3K79me2 persists in spermatozoa (Figure 4d and Supplementary Figure 8). Quantification of H3K79me2 revealed that the decrease observed in Sly-KD elongating/condensing spermatids persists in spermatozoa (when normalized to histone H3 level, see below, Supplementary Figure 7B and D).

Sly deficiency leads to reduced histone $\mathrm{H} 4$ acetylation prior to histone-to-protamine exchange. Extensive acetylation of histone $\mathrm{H} 4(\mathrm{acH} 4)$ is a hallmark of chromatin remodeling during spermatid differentiation and is detected at the same postmeiotic stages than H3K79 dimethylation, just prior to nucleosome eviction. ${ }^{31,32}$ It has recently been demonstrated that DOT1L-mediated H3K79me2 facilitates $\mathrm{acH} 4{ }^{34}$ We therefore tested whether acH 4 was impacted by 

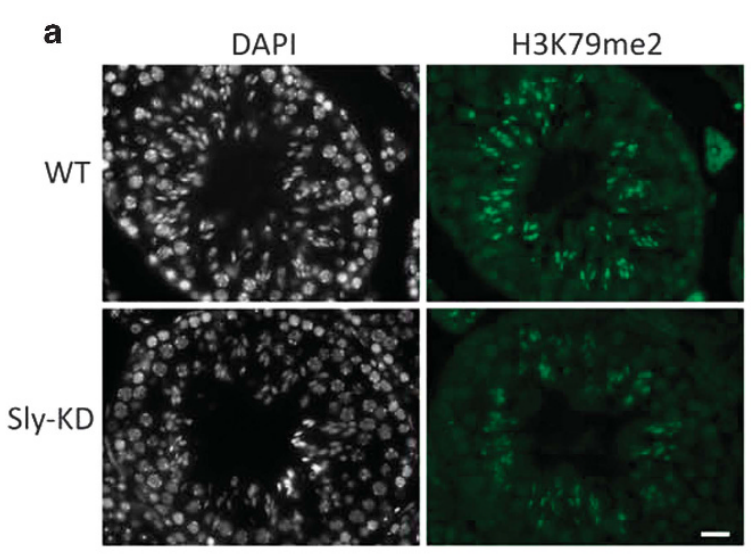

c

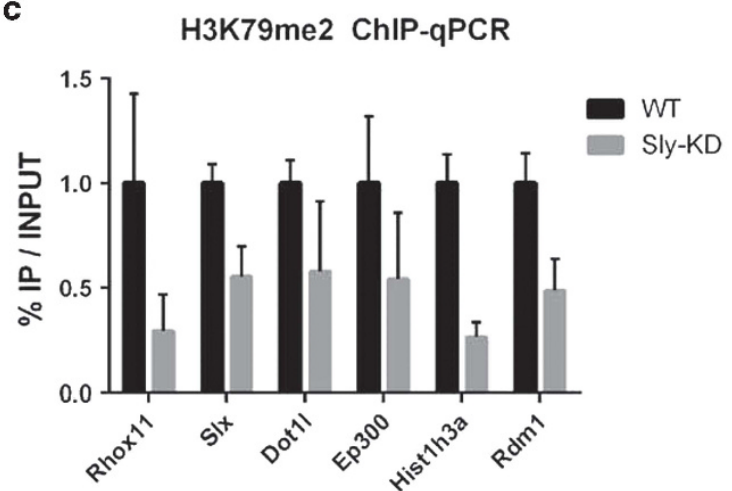

\section{b}

H3K79me2 level in elongating spermatids

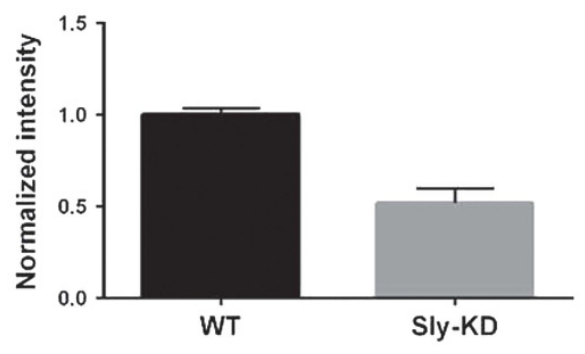

d

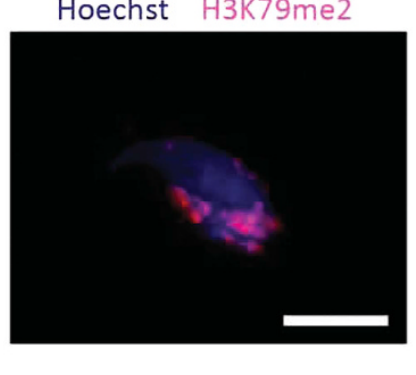

Figure 4 DOT1L-mediated H3K79 dimethylation is affected by Sly knockdown. (a) Immunofluorescence detection of H3K79 dimethylation (H3K79me2) in stage X testicular sections from WTand Sly-KD mice. Scale bar indicates $20 \mu \mathrm{m}$. Pictures were taken using the same image capture parameters (see also Supplementary Figure 6). (b) Schematic showing H3K79me2 level quantified by immunofluorescence in Sly-KD and WT step 10-12 elongating spermatids. The graph represents mean \pm S.E.M. The difference between the two genotypes is statistically significant ( $t$-test on six samples per genotype, $P=0.0002)$. (c) ChIP-qPCR experiments on elongating/condensing spermatids from WTand SlyKD mice, using antibody against H3K79me2. The $Y$-axis represents the mean enrichment (\% IP/input) \pm S.E.M. normalized to a negative control region (NC) located at $\sim 170 \mathrm{~kb}$ from a TSS, and to the corresponding WT value. A significant decrease of H3K79me2 level at gene TSS was found in Sly-KD compared to WT samples when considering all tested genes (t-test, $P<0.05, n=3-4$ samples per genotype). (d) Immunofluorescence detection of H3K79me2 (red) in WT epididymal spermatozoa. Hoechst (blue) was used to stain nuclei. Scale bar indicates $5 \mu \mathrm{m}$

Sly deficiency and found reduced level of acH4 in Sly-KD versus WT step 10-12 elongating spermatids by immunofluorescence (Figures 5a, b and Supplementary Figure 9). This was confirmed by ChIP-qPCR analyses in all tested sites (Figure 5c). Together, these data show that Sly deficiency affects chromatin remodeling during spermatid differentiation.

Defects in postmeiotic chromatin remodeling lead to a higher proportion of residual histones and increased DNA oxidation in Sly-deficient spermatozoa. Approximately $1-5 \%$ of histones remain in WT mouse spermatozoa. ${ }^{35}$ To determine whether abnormal chromatin marks in elongating spermatids have consequences on chromatin content in spermatozoa, we next compared the quantity of remaining histones in sperm and observed a $\sim 2.5$-fold increase in histone $\mathrm{H} 3$ and a $~ 2$.3-fold increase in TH2B in Sly-KD compared to WT spermatozoa (Figures $6 a$ and b). Using antibody against protamine 2 (Hup2B) we also detected a small $(\sim 20 \%)$ but significant decrease in the quantity of protamine 2 in Sly-KD compared to WT sperm (Figure 6c). No significant difference was observed for protamine 1 (data not shown).
Finally, we tested whether abnormal chromatin content could alter spermatozoa genome integrity by measuring the proportion of spermatozoa showing oxidation of their DNA (measurement of oxidized deoxy-guanosine, 8-oxo-dG). We found an average of $\sim 34 \%$ of WT spermatozoa with 8-oxo-dG staining, as described in other studies, ${ }^{36}$ and a significant increase to $~ 53 \%$ of 8-oxo-dG positive spermatozoa in Sly-KD epididymis (Figure 6d).

SLY interacts with TBL1XR1 and other members of the SMRT/N-Cor complex. To understand how SLY controls gene expression during sperm differentiation, we searched for its protein partners by co-immunoprecipitation followed by mass spectrometry. We used FLAG antibody to immunoprecipitate SLY and its partners on two types of materials: (i) testicular cells from a transgenic mouse model expressing SLY protein fused to a FLAG-tag (Supplementary Figure 10) and (ii) a spermatogonia cell line (GC1) transfected with a FLAG-SLY construct. WT testes and GC1 cells transfected with an empty vector were used as negative controls. Immunoprecipitated proteins were analyzed by liquid chromatography coupled to tandem mass spectrometry 
a

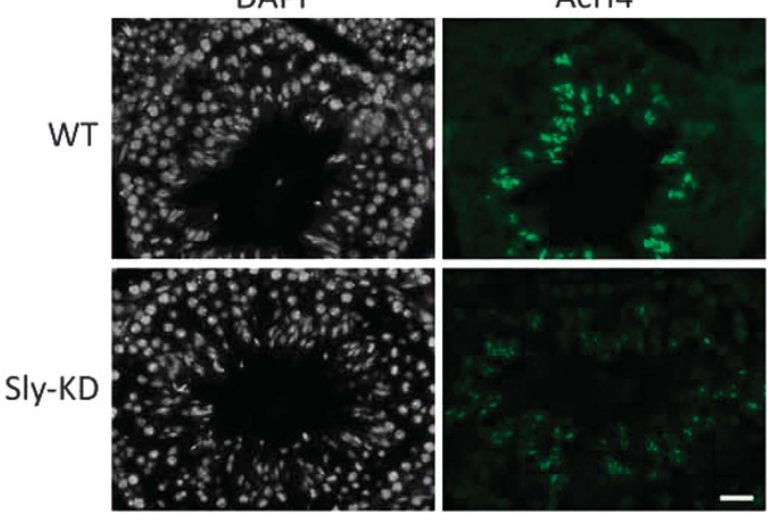

b

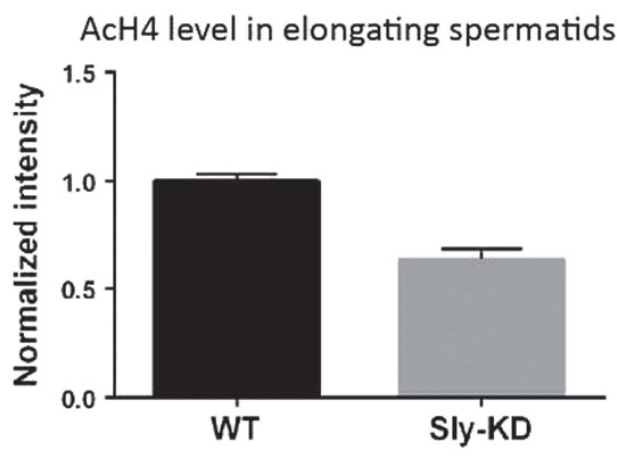

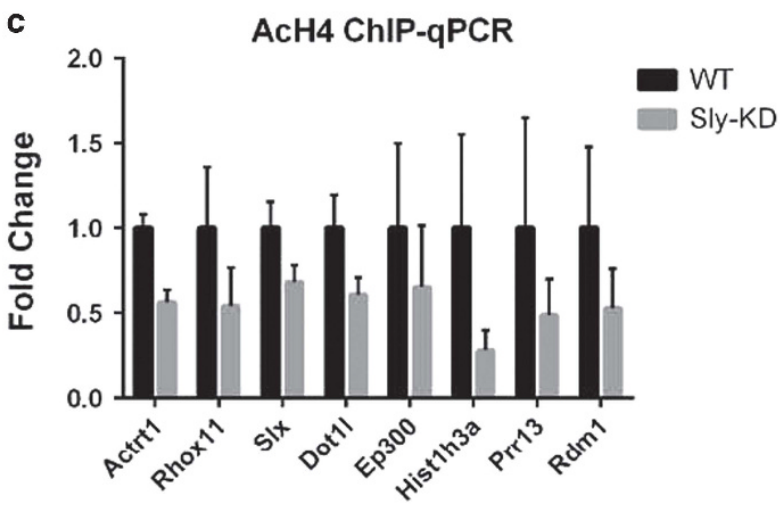

Figure 5 Sly deficiency impairs histone $\mathrm{H} 4$ hyperacetylation during postmeiotic sperm differentiation. (a) Immunofluorescence detection of histone $\mathrm{H} 4$ acetylation (acH4) in stage XII testicular sections from WT and Sly-KD mice. Scale bar indicates $20 \mu \mathrm{m}$. Pictures were taken using the same image capture parameters (see also Supplementary Figure 9). (b) Schematic showing acH4 level quantified by immunofluorescence in Sly-KD and WT step 10-12 elongating spermatids. The difference between the two genotypes is statistically significant ( $t$-test on 5-6 samples per genotype, $P=0.00012)$. (c) ChIP-qPCR experiments on elongating/condensing spermatids from WT and Sly-KD mice, using antibody against acH4. The $Y$-axis represents the mean enrichment (\% IP/input) \pm S.E.M. normalized to the corresponding WT value. A significant decrease of acH4 level was found in Sly-KD compared to WT samples when considering all tested genes ( $t$-test, $P<0.01, n=3-4$ samples per genotype)

(LC-MS/MS). Two complementary approaches (MASCOT and label-free quantification (LFQ) Maxquant analysis) were used to analyze LC-MS/MS data. They showed that TBL1XR1 and several other members of the SMRT/N-CoR repressive complex (TBL1X, NCOR1 and HDAC3) were specifically immunoprecipitated with SLY (Table 3). Interaction of SLY and TBL1XR1 was confirmed in WT and FLAG-SLY transgenic testes by western blot following immunoprecipitation using anti-SLY, anti-FLAG or anti-TBL1XR1 antibody (Figure 7).

\section{Discussion}

In the present paper, we investigated the molecular role of SLY and the consequences of its absence on chromatin structure; based on acquired data we identified novel regulators of postmeiotic gene expression and of chromatin remodeling during sperm differentiation.

SLY and the regulation of postmeiotic gene expression. First, we found that SLY protein is present at the TSS of thousands of genes relevant to postmeiotic cell identity, with a known role during postmeiotic differentiation and/or significantly upregulated postmeiotically. We also showed that SLY overlaps with active chromatin marks, such as
H3K4me3 or Kcr. Comprehensive transcriptome analyses of Sly-deficient postmeiotic germ cells demonstrated that Sly deficiency does not switch on genes normally silent in postmeiotic cells but rather modulates the expression level of $>1000$ genes expressed postmeiotically. Sly deficiency chiefly induces upregulation of $X Y$ genes $(37 \%$ of all deregulated genes) with no $X Y$ gene found downregulated, while hundreds of autosomal genes are either upregulated or downregulated (respectively $30 \%$ and $33 \%$ of all deregulated genes). The consequences of Sly deficiency on postmeiotic gene expression are therefore different for $X Y$ genes compared to autosomal genes, suggesting distinct regulatory mechanisms, probably due to a different chromatin environment. Indeed, postmeiotically, the XY chromatin significantly differs from that of autosomes as a consequence of the meiotic silencing of sex chromosomes. ${ }^{37,38}$

How does SLY control gene expression? Despite the fact that SLY is related to SYCP3, a protein of the meiotic synaptonemal complex which has been proven to bind double-stranded DNA, ${ }^{14,17,39}$ the mechanism by which SLY regulates genes remained elusive. Indeed, SLY-SYCP3 conservation is relatively low ( $28 \%$ of identity) and SLY, contrary to SYCP3, is very acidic (with an isoelectric point $\sim 4.8$ ); this most likely precludes direct DNA binding and rather 
a
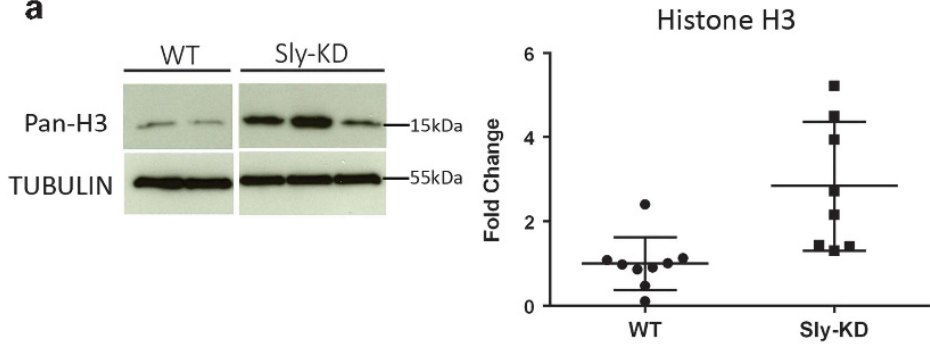

b

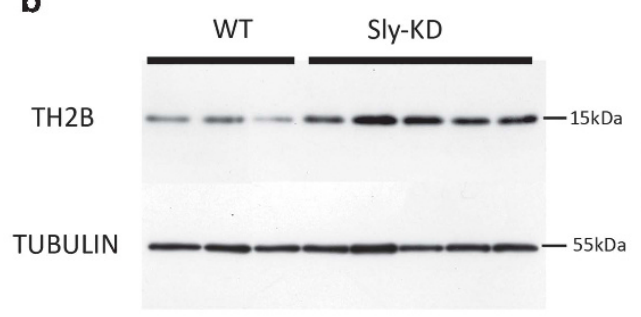

C

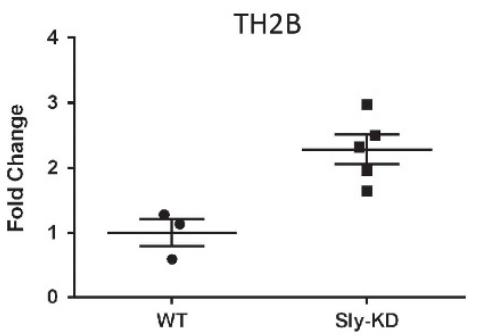

Hup2B

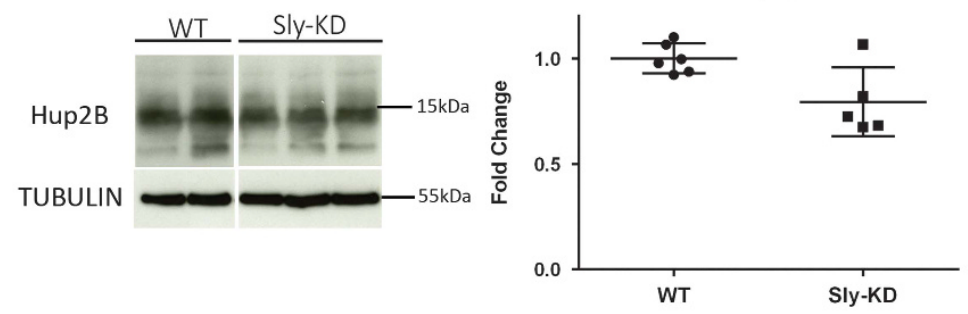

d

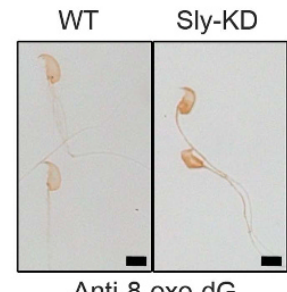

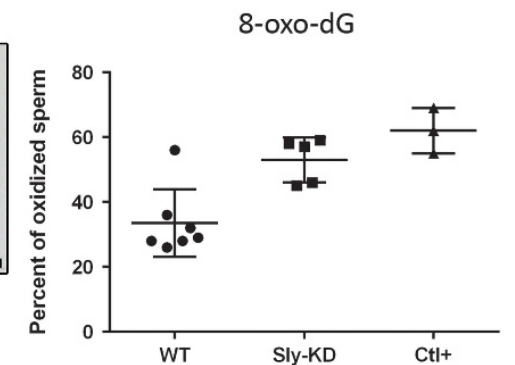

Figure 6 Sly deficiency leads to abnormal chromatin content and increased DNA oxidation in spermatozoa. (a) Western blot quantification of histone H3 (using anti-pan-H3) in protein extracts from WT and Sly-KD spermatozoa. Antibody against TUBULIN was used to normalize the signal. The scatter plot on the right represents histone H3 level normalized with TUBULIN (mean value \pm S.D.). The difference between the two genotypes is statistically significant ( $t$-test on $8-9$ samples per genotype, $P=0.0047$ ). (b) Western blot detection and quantification of TH2B in protein extracts from WT and Sly-KD spermatozoa. Antibody against TUBULIN was used to normalize the signal. The right panel is a scatter plot showing quantification of TH2B (normalized to TUBULIN level) in Sly-KD and WT spermatozoa. The graph represents the mean level \pm S.E.M. The difference between the two genotypes is statistically significant ( $t$-test, $n=3-5$ samples per genotype, $P=0.009$ ). (c) Western blot quantification of protamine 2 (using antiHup2B) in protein extracts from WT and Sly-KD spermatozoa. Antibody against TUBULIN was used to normalize the signal. The scatter plot on the right represents Protamine 2 level normalized with TUBULIN (mean value \pm S.D.). The difference between the two genotypes is statistically significant ( $t$-test on $5-6$ samples per genotype, $P=0.0199$ ). The variability was elevated among Sly-KD samples and when excluding one outsider value, the $P$-value dropped to 0.0003 . (d) Representative pictures obtained using antibody against 8-oxo-dG in WT and Sly-KD epididymal spermatozoa. WT picture shows two 8-oxo-dG negative spermatozoa while Sly-KD picture shows two 8-oxo-dG positive spermatozoa. Pictures were taken using the same image capture parameters. Scale bar indicates $5 \mu \mathrm{m}$. The scatter plot on the right represents the percentage of oxidized spermatozoa (mean \pm S.D.) measured using antibody against 8-oxo-dG. Ctl+ indicates values obtained when spermatozoa were pre-incubated with $\mathrm{H} 202$ (positive control). Mann-Whitney nonparametric test showed significant difference between WT and Sly-KD samples (5-7 samples per genotype, $P=0.01)$ and between WT and Ctl+ $(P=0.025)$

suggests that SLY is part of a protein complex able to recruit regulators of gene expression, including proteins with DNA-binding domains. In that respect, our findings that SLY interacts with TBLX1R1 and other members of the SMRT/NCoR complex provide an interesting model. This complex, expressed in many tissues, contains five proteins (NCOR1,
HDAC3, GPS2, TBL1XR1 and TBL1X) and has been shown to interact with nuclear hormone receptors, transcription factors or chromatin modifying enzymes. ${ }^{40-43}$ The recruitment/ release of SMRT/N-CoR complex on repressed gene promoters is a dynamic process ${ }^{44,45}$ on which SLY could act to control gene expression. Further studies will be required to 
Table 3 Mass spectrometry results from MASCOT and LFQ Maxquant analysis

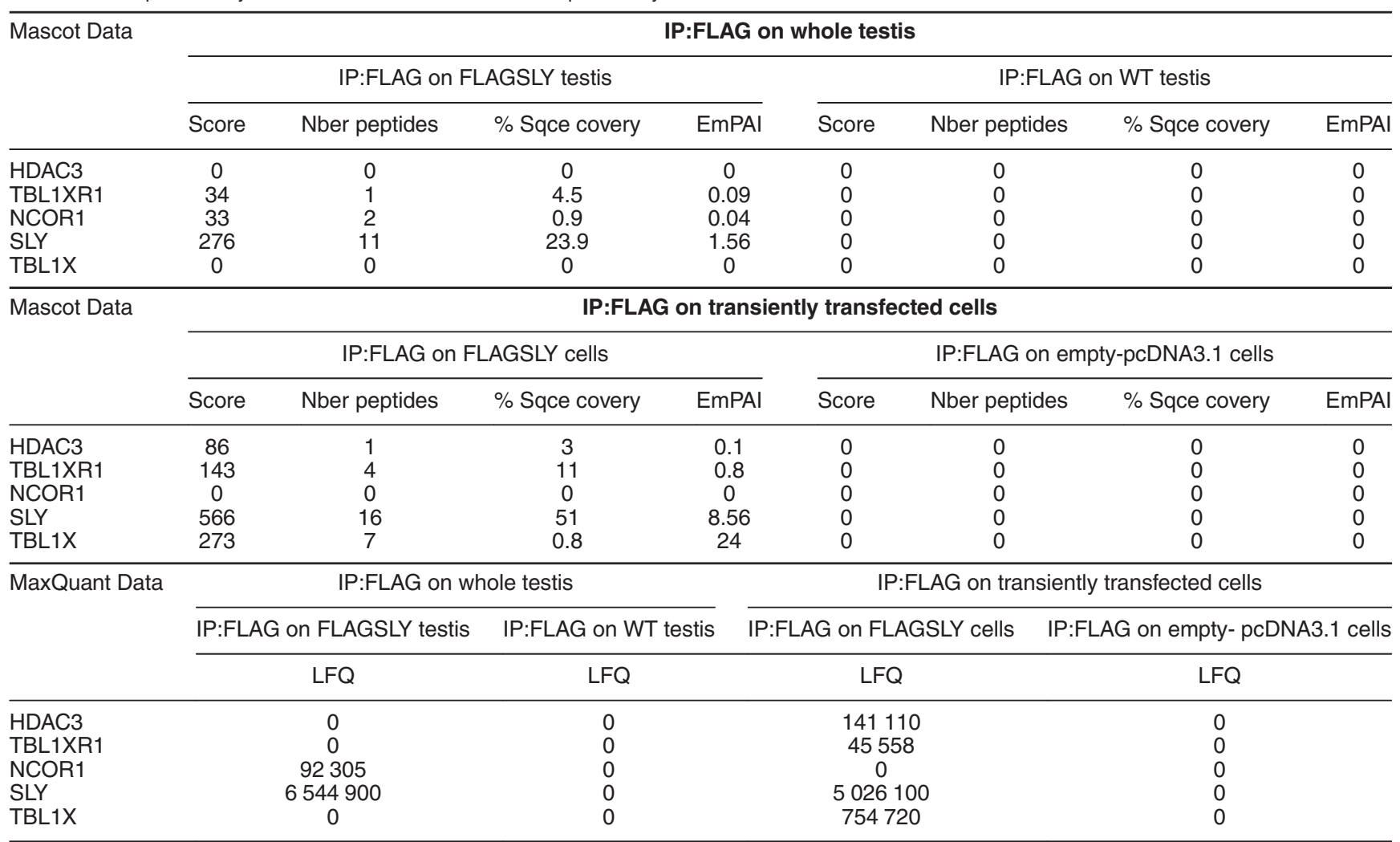

Abbreviations: EmPAI, Exponentially Modified Protein Abundance Index; LFQ, label-free quantification

Top panel: MASCOT analysis of the co-immunoprecipitation assay performed on whole testis and of the co-immunoprecipitation assay performed on GC1 cells. The protein score is the sum of the highest MS/MS ions score for each distinct peptide sequence. The highest the protein score, the more it is represented in the sample. However, for an identical mole of protein, a larger protein can give more peptides than a smaller one. EmPAI value provides a complementary information as it depends on the number of detected peptides compared to the total number of detectable peptides. The higher the EmPAI, the more abundant the protein.

Bottom panel: Maxquant LFQ analyses of the co-immunoprecipitation assay performed on whole testis and of the co-immunoprecipitation assay performed on GC1 cells. Maxquant analysis is more accurate than EmPAI because it reflects the total LC-MS intensity of peptides for the proteins

characterize the role of SMRT/N-Cor complex in the context of sperm differentiation.

By gene ontology analyses, we showed that many of SLYtargets are involved in gene regulation and chromatin modification. Focusing on those genes, we found that SLY regulates $\mathrm{XY}$-encoded $\mathrm{H} 2 \mathrm{~A}$ variants and DOT1L, a promising candidate for the chromatin remodeling defects observed in Sly-KD spermatids (see below).

The sex chromosomes encode several H2A variants, all of which are particularly, if not specifically, expressed in spermatids. ${ }^{7,27-29}$ We found that all of them are upregulated in Sly-KD round spermatids and that H2A.B3, known to be enriched at the start of active genes, ${ }^{27}$ is more incorporated in Sly-KD than in WT spermatid chromatin. Several other genes encoding histones are also SLY-targets (both enriched in SLY at their TSS and deregulated when Sly is knocked down), such as Hist1h3 and Hist1h4 clusters, ${ }^{15} \mathrm{H} 1 \mathrm{fnt}$ and so on. Their deregulation could also contribute to the gene deregulation and abnormal chromatin remodeling observed in Sly-deficient spermatids.

It is quite intriguing that SLY controls the expression of essential and evolutionary conserved genes but is itself not conserved throughout evolution. ${ }^{15,46,47}$ Indeed, Sly has been shown to be involved, together with its X-linked homolog $S / x$, in an intragenomic conflict in which an unbalanced number of $S / y$ versus SIx gene copies leads to transmission distortion. ${ }^{33}$ The fact that SLY regulates chromatin components fits with the observation that transmission distorters are often involved in gene/chromatin regulation processes. ${ }^{48}$

SLY and chromatin remodeling during sperm differentiation. We particularly investigated Dot1/and the consequence of its downregulation, as it is an interesting candidate gene involved in spermatid chromatin remodeling and histone-toprotamine replacement. DOT1L is the principal H3K79 methyltransferase identified to date and is ubiquitously expressed and conserved throughout evolution. ${ }^{49,50}$ During spermatogenesis, it has been shown to be expressed in spermatocytes $^{51}$ and spermatids; ${ }^{31,32}$ here, we show that Dot $1 /$ is actually expressed at a higher level in spermatids compared to spermatocytes or spermatogonia. In elongating spermatids, high H3K79me2 coincides with histone $\mathrm{H} 4$ hyperacetylation, just prior to histone removal. ${ }^{31,32}$ Using our mouse model, we showed that postmeiotic downregulation of Dot $1 /$ induced by Sly deficiency leads to reduction in H3K79me2 and in acH4 levels in elongating spermatids. At 
a

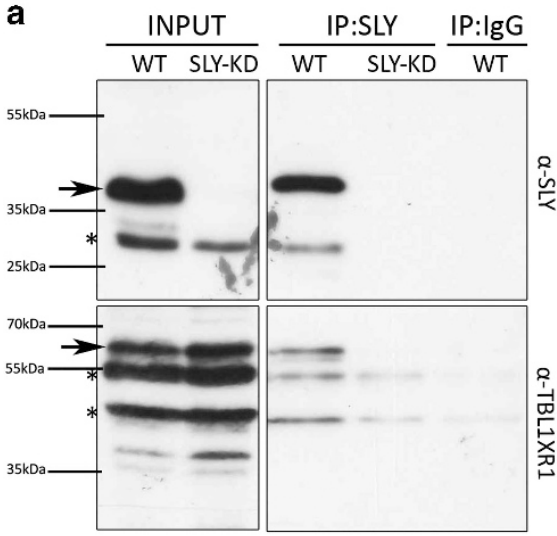

C

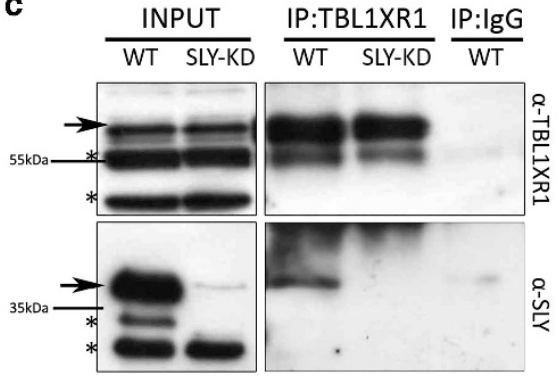

b

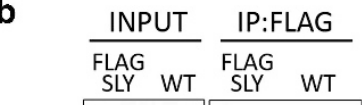

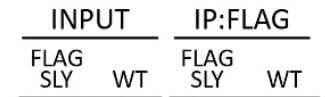

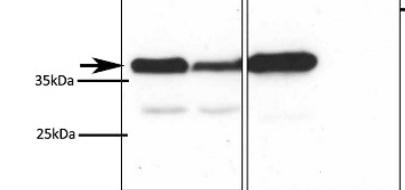

$\alpha$-SLY detection

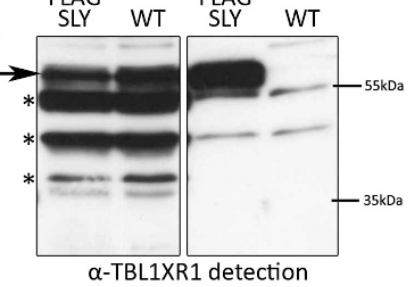

$\alpha$-TBL1XR1 detection

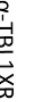

Figure 7 SLY protein interacts with TBL1XR1 protein. (a) SLY and TBL1XR1 antibody detection of WT and Sly-deficient (Sly-KD) whole-testicular extracts (INPUT) and of corresponding extracts immunoprecipitated with SLY antibody (IP:SLY). SLY immunoprecipitation performed on Sly-KD testicular extracts and immunoprecipitation with purified rabbit IgG on WT extracts (IP:IgG) were used as negative controls. (b) SLY and TBL1XR1 antibody detection of whole-testicular extracts from WT and FLAG-SLY mice (INPUT) and of corresponding extracts immunoprecipitated with FLAG antibody (IP:FLAG). FLAG immunoprecipitation performed on WT testicular extracts was used as a negative control. (c) SLY and TBL1XR1 antibody detection of WT whole-testicular extracts (INPUT) and immunoprecipitated with TBL1XR1 antibody (IP:TBL1XR1). TBL1XR1 immunoprecipitation performed on Sly-KD testicular extracts and immunoprecipitation with purified rabbit IgG on WT extracts (IP:IgG) were used as negative controls. Arrows indicate the specific band (at expected sizes of 38kDa for SLY and 64kDa for TBL1XR1) and stars, non-specific bands (which disappear in negative controls)

the end of the differentiation process, Sly-KD spermatozoa display a moderate but significant alteration in spermatozoa chromatin content, with more residual histones, and less protamination ( $20 \%$ reduction). We propose this is a consequence of the abnormal spermatid chromatin composition resulting from the deregulation of genes essential to spermatid chromatin remodeling, in particular of DOT1L (Figure 8). It has recently been shown that DOT1L-mediated $\mathrm{H} 3 \mathrm{~K} 79$ me2 facilitates histone $\mathrm{H} 4$ acetylation in the context of MLL leukemia, ${ }^{34}$ and that BRD4-mediated acetylation promotes chromatin decompaction and nucleosome eviction. ${ }^{52}$ We propose that, in the context of sperm differentiation, DOT1L and H3K79me2 play a critical role in $\mathrm{H} 4$ acetylation which itself is required for an open chromatin state enabling nucleosome removal prior to protamine incorporation.

Finally, we show that abnormal chromatin content and compaction of Sly-KD spermatozoa is associated with increased susceptibility to oxidative stress. This could also explain the increase in sperm DNA breaks that was previously observed. ${ }^{16}$ A modest reduction in protamine levels ( 33\%) in mice haploinsufficient for Prm1 or Prm2 gene results in reduced sperm compaction, increased DNA damage and embryo lethality. ${ }^{9}$ Experiments in which Sly-KD sperm were directly injected into the oocytes (i.e., intracytoplasmic sperm injection, ICSI) have shown that Sly deficiency does not dramatically impair the early post-fertilization events and does not lead to gross paternal chromosome breaks in the zygotes. ${ }^{16}$ But, in light of the high incidence of sperm with oxidized DNA in Sly-KD males that we reported here, ICSI with Sly-KD sperm may produce offspring with increased mutational load. If not properly repaired, DNA lesions such as oxidized deoxy-guanosine (8-oxo-dG) can indeed lead to mutations. Despite the existence of DNA repair strategies in the mammalian zygote, studies have shown deleterious consequences on genome integrity and embryo development when incidence of DNA lesions is too high. ${ }^{13,36,53}$ Oxidative damage to sperm DNA resulting from age, environmental or lifestyle factors (such as smoking), has been shown to be associated with increased incidence of diseases (such as cancers, neurological disorders, etc.) in the progeny. ${ }^{54}$ Oxidative stress associated with impaired chromatin remodeling in case of male infertility could similarly have negative consequences on the health of children conceived using ICSI to bypass the father's infertility. Further studies using relevant models will be needed to address this question.

\section{Material and Methods}

ChIP-Seq analyses. SLY ChIP-Seq was performed by Active Motif ChIPSequencing service, as follow: $~ 10$ million of FACS-sorted enriched fractions of round spermatids (with a purity $>90 \%$ ) were fixed with $1 \%$ formaldehyde for 15 min then quenched with $0.125 \mathrm{M}$ glycine. Chromatin was isolated by adding lysis buffer, 


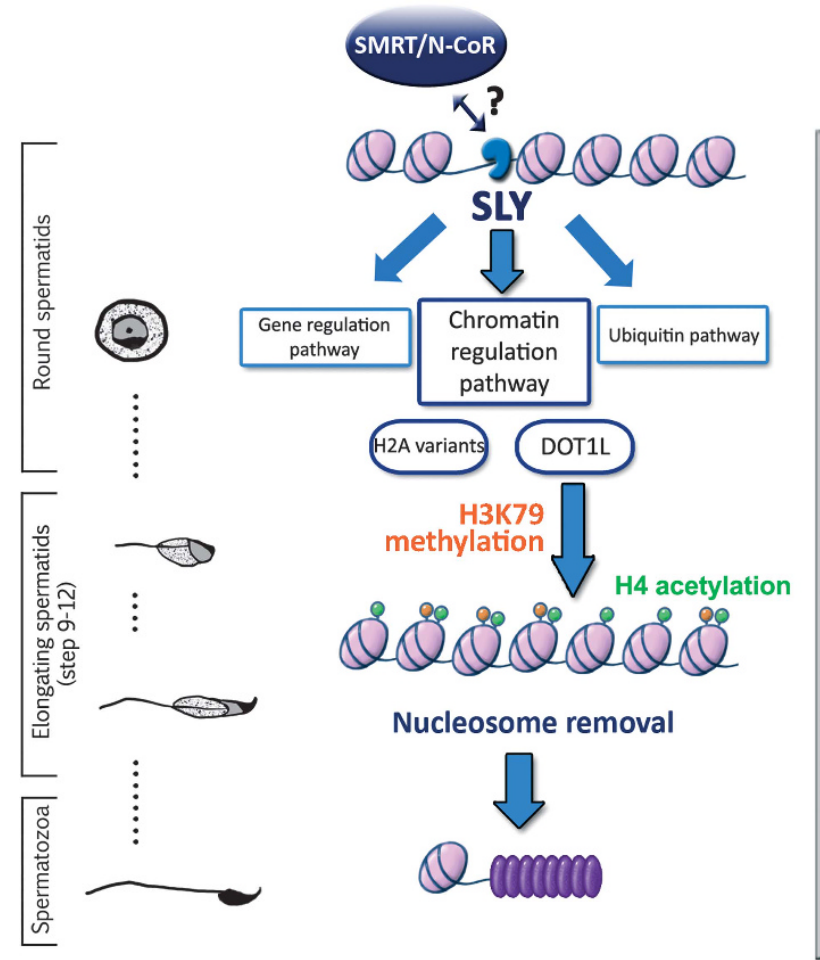

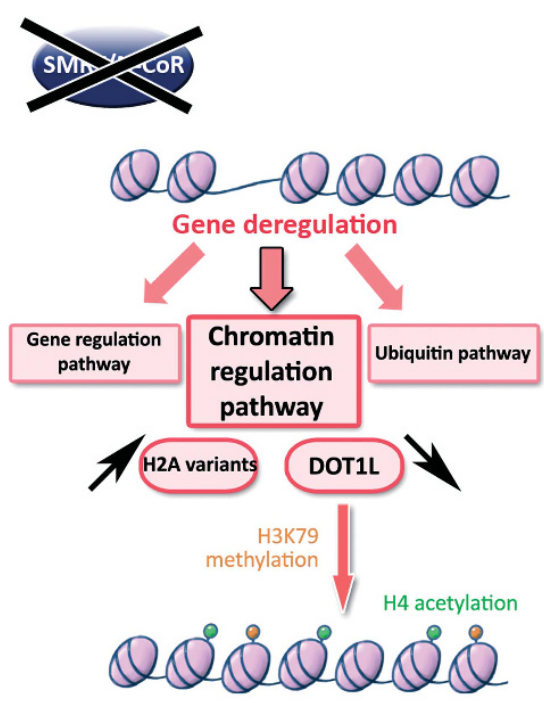

Less efficient nucleosome removal

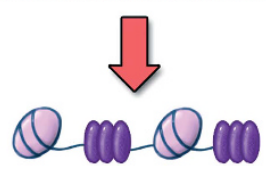

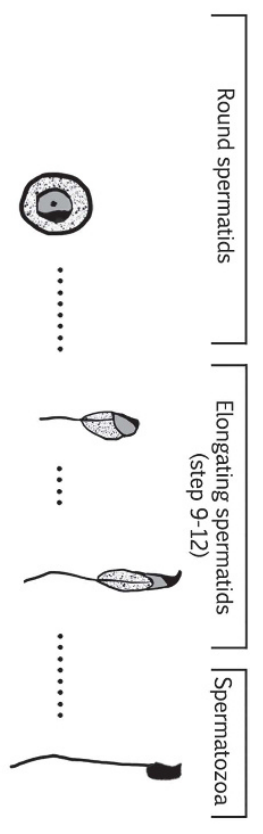

Figure 8 Model presenting the mechanism by which SLY controls gene expression and chromatin remodeling during sperm differentiation. In WT round spermatids (left panel), SLY (in blue) interacts with the SMRT/N-CoR complex (which comprises TBL1XR1, TBL1X, NCOR1 and HDAC3) and is located at the start of genes involved in gene regulation, chromatin regulation and the ubiquitin pathway. In particular, SLY directly controls the expression of X-chromosome-encoded genes coding for H2.A variants (such as H2A.B3) and of the H3K79 methyltransferase DOT1L. In elongating spermatids, there is a wave of H3K79 dimethylation (orange circles) and of histone H4 acetylation (green circles); those modifications are expected to be a prerequisite to the efficient removal of nucleosomes (light pink oval) and replacement by protamines (purple oval), a process which is required to achieve optimal compaction of the spermatozoa nucleus. When SLY is knocked down (right panel), X-encoded H2.A variants are upregulated and more incorporated in the spermatid chromatin, while DOT1L is downregulated. DOT1L downregulation leads to a decrease in dimethylated H3K79 and acetylated histone H4 in elongating spermatids. Alterations in the spermatid chromatin structure affect the replacement of nucleosomes by protamines and lead to a higher proportion of nucleosomes and a decreased proportion of protamines. As a result, Sly-deficient spermatozoa are abnormally shaped, less compact and present a higher susceptibility to DNA damage than WT spermatozoa

followed by disruption with a Dounce homogenizer. Lysates were sonicated and the DNA sheared to an average length of 300-500 bp. Genomic DNA (input) was prepared by treating aliquots of chromatin with RNase, proteinase $\mathrm{K}$ and heat for de-crosslinking, followed by ethanol precipitation. Pellets were resuspended and the resulting DNA was quantified on a NanoDrop spectrophotometer. Extrapolation to the original chromatin volume allowed quantitation of the total chromatin yield. An aliquot of chromatin $(30 \mu \mathrm{g})$ was precleared with protein A agarose beads (Life technologies, Carlsbad, CA, USA). Genomic DNA regions of interest were isolated using $12 \mu \mathrm{g}$ of anti-SLY antibody. ${ }^{14}$ Complexes were washed, eluted from the beads with SDS buffer, and subjected to RNase and proteinase $\mathrm{K}$ treatment. Crosslinks were reversed by incubation overnight at $65^{\circ} \mathrm{C}$, and ChIP DNA was purified by phenol-chloroform extraction and ethanol precipitation. Illumina sequencing libraries were prepared from the ChIP and input DNAs using the Apollo 324 system (WaferGen, Fremont, CA, USA). After a final PCR amplification step, the resulting DNA libraries were quantified and sequenced on HiSeq 2500 (37 and 26 million of reads were obtained for ChIP and input DNAs, respectively).

Bioinformatics. SLY ChIP and input sequences (50-nt reads, single end) were aligned to the mouse genome (GRCm38/mm10) using BWA algorithm, ${ }^{55}$ and filtered by mapping quality using Samtools $-\mathrm{q} 0 .^{56}$ For reads with multiple good alignments, one alignment was reported at random. Alignments were extended in silico at their $3^{\prime}$-ends to a length of $200 \mathrm{bp}$, which is the average genomic fragment length in the size-selected library, and assigned to 32-nt bins along the genome. The resulting histograms (genomic 'signal maps') were stored in BAR and bigWig files. Data sets have been submitted to SRA http://www.ncbi.nlm.nih.gov/sra with accession number SRP055115. Sly peak locations were determined using the
MACS algorithm (v1.4.2) ${ }^{57}$ with a cutoff of $P=1 \mathrm{e}-7$. Annotation of SLY-enriched genomic regions (Figure $1 \mathrm{a}$ and Supplementary Figure $1 \mathrm{~A}$ ) was performed using Cis-regulatory Element Annotation System available at http://liulab.dfci.harvard.edu/ CEAS/index.html. $P$-values for the significance of the relative enrichment with respect to the background were calculated using one-sided binomial test. BED files containing SLY ChIP-Seq regions (WT and Sly-KD) were intersected with Ensembl80 gene coordinates (gene start, or gene start $\pm 1 \mathrm{~kb}$ ). Graphical representation of enrichment around the start of genes (expressed and not expressed in round spermatids) was done using Profiler and ComputeMatrix tools ${ }^{58}$ available at the Galaxy website https://mississippi.snv.jussieu.fr/. Round spermatids ChIP-Seq data sets for H3K4me3, H3K27me, Kcr and H3K9me3 were obtained from GSE42629, GSE32663 and GSE56526. ${ }^{19-21}$ All data sets were re-analyzed using the last version of the mouse genome (GRCm38/mm10) as described in Moretti et al. ${ }^{38}$ Overlap comparison was achieved by intersecting the intervals of two ChIP-Seq data sets. Graphic representations of ChIP-Seq data were performed using IGV (Integrative Genomics Viewer, https://www.broadinstitute.org/igv/). Gene ontology analyses were performed using Genomatix (https://www.genomatix.de/), GSEA (http://www.broadinstitute.org/gsea/) ${ }^{59}$ and EnrichR (http://amp.pharm.mssm. edu/Enrichr/). ${ }^{60}$

Microarray and RNA-Seq analyses. From Illumina microarray WG6 v2 of Sly-KD versus WT round spermatids, ${ }^{15}$ all genes $>1.5 \times$ fold deregulated (i.e., Log2 ratio $<-0.58$ or $>0.58$ ) with a $P$-value $\leqslant 0.05$ were converted to ENSEMBL ID using Biomart (http://www.ensembl.org/biomart) and the last version of the mouse genome (GRCm38/mm10). Close paralogs ( $>70 \%$ identity) were added to $>1.5 \times$ extended to close paralog list (752 genes in total). All genes significantly 
deregulated with a $P$-value $\leqslant 0.05$ were converted to ENSEMBL ID using Biomart and $\mathrm{mm} 10$ version of the mouse genome. This gave a list of 1171 deregulated genes. Gene expression data from human testicular biopsies were obtained from published microarray data set (ArrayExpress: E-TABM-234). ${ }^{61}$ Gene expression data of mouse purified germ cells were obtained from RNASeq data sets GSE35005 and GSE43717 $7^{6,18}$ and analyzed by GenoSplice (http://www.genosplice. com) using the following parameters: reads were aligned onto the mouse genome (Ensembl 75, mm10) using STAR v.2.3.0, with an exon-exon junction database built using annotations from Ensembl version 75. For each gene present in ENSEMBL, reads aligning on constitutive regions (that are not prone to alternative splicing) were counted. Based on these read counts, normalization and differential gene expression were performed using DESeq (v1.12.0 on R v3.0.0).

Mice. All animals used in the present study were on $>90 \% \mathrm{C} 57 \mathrm{BL} / 6$ background and processed at adult age (between 2- and 6-month old males). Sly-KD mice were obtained as described in Cocquet et al. ${ }^{15}$ FLAG-SLY1 transgenic mice were obtained by pronuclear micro-injection of a linearized construct containing Sly1 open reading frame (i.e., Sly long and main isoform, see Riel et l. $^{16}$ fused with Flag sequence, under the control of the spermatid-specific promoter SP-10 (aka ACRV1). ${ }^{62,63}$ Fertilized eggs from CBA/Ca x C57BL/10 mating were microinjected with the construct, using standard protocols. Transgenic founders carrying the SP10-FLAG-SLY1 construct were identified by PCR using the following primers (35 cycles, annealing temperature $60^{\circ} \mathrm{C}$ ): Flag-F primer: $5^{\prime}$-GGA CTA CAA GGAC GA CGA TGA CAA-3' and Flag-R primer: 5'- GCA GCC TGC ACC TGA GGA GT-3' (711 bp).

Several founders were obtained and crossed with XYRIII males on a random-bred MF1 albino (National Institute for Medical Research colony) background. One line (called FLAG-SLY) was established from a male founder which transmitted the transgene with a similar expression of FLAG-SLY1 compared to endogenous SLY1 protein. The line was maintained by further backcrossing transgenic males and females to B6/N mice and generate XYRIII males with (tsgic) and without (neg sib) the transgene. RT-qPCR and Western blot experiments showed a 2-fold increase in Sly transcript and protein level in FLAG-SLY compared to WT testes. By immunofluorescence on FLAG-SLY and WT testicular tubules it was observed that FLAG-SLY transgene was only expressed in round spermatids (Supplementary Figure 10).

For all experiments, WT controls were of same age and background (i.e., nontransgenic siblings from the same mating). Animal procedures were subjected to local ethical review (Comite d'Ethique pour l'Experimentation Animale, Universite Paris Descartes; registration number CEEA34.JC.114.12).

Germ cell purification by FACS. Testicular cells were isolated from one adult male per experiment following a protocol adapted from ${ }^{64}$ with some modifications previously described in Comptour et al. ${ }^{65}$ Cell purity was assessed for each collected fraction by microscope observation following DAPI (4,6-diamidino-2phenylindole) staining (VECTASHIELD Mounting Medium with DAPI, Vectorlab, Burlingame, CA, USA) of cells spread onto glass slides and fixed with $4 \%$ buffered paraformaldehyde. Round spermatids and elongating spermatids were collected with a purity $>90 \%$.

Germ cell purification by elutriation. Enriched fractions of round spermatids and elongating/condensing spermatids were obtained using two to three mice per experiment (i.e., 4-6 testes) by centrifugal elutriation as described previously. ${ }^{15}$ Cell purity was assessed for each collected fraction as described above. Only fractions with $>90 \%$ purity were used for ChiP-qPCR analyses. It has previously been shown that Sly-KD and WT testicular tubules contain the same proportion of each type of round spermatids, ${ }^{15}$ elutriated Sly-KD and WT round spermatid fractions can therefore be compared.

Collection of epididymal spermatozoa. Cauda epididymides were dissected out from 2- to 6-month-old males, freed of connective tissues and fat, and transferred to a small petri dish containing $1 \mathrm{ml}$ of M2 medium (Sigma-Aldrich, Saint-Louis, MO, USA). Using small pipette tips, spermatozoa cells were very gently squeezed out of cauda epididymides, to limit contamination with somatic cells. Following $5 \mathrm{~min}$ of incubation at $37^{\circ} \mathrm{C}$, sperm suspensions were collected and counted using a Malassez hemocytometer. Sperm cell purity was assessed for each sample by microscope observation following DAPI (4,6-diamidino-2-phenylindole) staining (VECTASHIELD Mounting Medium with DAPI, Vectorlab) of sperm cells spread onto glass slides and fixed with $4 \%$ buffered paraformaldehyde. All samples used in our analyses contained $\geqslant 99 \%$ of spermatozoa. Samples were aliquoted to five millions of spermatozoa per tube then centrifuged ( $600 \mathrm{~g}$ for $5 \mathrm{~min}$ ) and washed once in $1 \times$ PBS (Life technologies). Pellets were flash-frozen in liquid nitrogen.

SLY ChIP prior to qPCR. About $5 \times 10^{6}$ elutriated round spermatids (collected from two to three mice per sample) were crosslinked for $10 \mathrm{~min}$ at room temperature in $1 \times$ PBS containing $1 \%$ PFA. Reaction was stopped by adding $125 \mathrm{mM}$ Glycine and incubating for $5 \mathrm{~min}$ at room temperature. Cells were washed twice with ice-cold PBS and centrifuged at $500 \mathrm{~g}, 4^{\circ} \mathrm{C}$ for $10 \mathrm{~min}$. Cells were resuspended in $600 \mu \mathrm{l}$ of Lysis buffer $(50 \mathrm{mM}$ Tris pH 7.4, $300 \mathrm{mM} \mathrm{NaCl}, 0.1 \%$ NP-40, 0.1\% DOC, $1 \mathrm{mM}$ DTT) with Complete Protease Inhibitor Cocktail Tablets EDTA-free (Roche, Basle, Switzerland), $1 \mathrm{mM}$ PMSF $1 \mathrm{mM}$ and $10 \mathrm{mM}$ Aprotinin added extemporaneously, and incubated on ice for $30 \mathrm{~min}$. The suspension was then sonicated using PICO-Diagenode to obtain fragments of approximate size of 500 bp (as verified by 2100 Bioanalyzer, Agilent, Santa Clara, CA, USA). The lysate was centrifuged at $10000 \mathrm{~g}$ at $4{ }^{\circ} \mathrm{C}$ for $5 \mathrm{~min}$. Twenty microliter of supernatant were taken as input and the remaining supernatant was incubated on a rotating wheel at $4^{\circ} \mathrm{C}$ overnight with Protein G Dynabeads (Life Technologies) which were previously coupled with antibody against $S L Y,{ }^{14}$ as recommended by the manufacturer. The following day beads were washed subsequently in Lysis buffer, wash buffer no. 2 (50 mM Hepes pH7.4, 0.5M NaCl, 5 mM EDTA, 1\% Triton, 0.1\% NaDeoxycholate), wash buffer no. $3(10 \mathrm{mM}$ Tris- $\mathrm{HCl}$ pH8, $0.25 \mathrm{M} \mathrm{LiCl,} 0,5 \% \mathrm{NP}-40,0.5 \%$ NaDeoxycholate, $5 \mathrm{mM}$ EDTA ph8) and in TE buffer. Supernatant was completely removed and beads were resuspended in Elution buffer containing $1 \%$ SDS. Input was defrosted on ice and diluted in Elution buffer. Samples were incubated for $15 \mathrm{~min}$ at $65^{\circ} \mathrm{C}$ with gentle mix every $2 \mathrm{~min}$. IP and input were reverse crosslinked overnight at $65^{\circ} \mathrm{C}$. Samples were then treated with Proteinase $\mathrm{K}$ and incubated for $1 \mathrm{~h}$ at $37^{\circ} \mathrm{C}$. IP and input DNAs were purified using NucleoSpin Kit (MachereyNagel, Hoerdt, France) and eluted in $50 \mu$ l of distilled water. Experiments were repeated on independent pools of elutriated round spermatids (each representing 2-3 mice) three to six times. $T$-test was used for statistical analyses.

H2A.B3 ChIP prior to qPCR. Mononucleosomes were prepared from elutriated round spermatids ( $>90 \%$ purity) as previously described in Montellier et al. ${ }^{11}$ with some modifications. Briefly, about $5 \times 10^{6}$ round spermatids purified by elutriation were lysed by incubation with $300 \mu$ l of lysis buffer $(\mathrm{KCl} 60 \mathrm{mM}, \mathrm{NaCl}$ $15 \mathrm{mM}$, Tris HCl pH $7.415 \mathrm{mM}$, Saccharose 0.34 M, EDTA 2 mM, EGTA $0.5 \mathrm{mM}$, Spermidine $0.65 \mathrm{mM}$, DTT $1 \mathrm{mM}$, Triton $0.03 \%$, Glycerol 1\%, Complete Protease Inhibitor Cocktail Tablets Roche EDTA-free, PMSF $1 \mathrm{mM}$, Aprotinin $10 \mathrm{mM}$ ) for $20 \mathrm{~min}$ on ice, followed by centrifugation at $500 \mathrm{~g}$ at $4{ }^{\circ} \mathrm{C}$ for $10 \mathrm{~min}$. The pellet was gently resuspended in $200 \mu$ l of wash buffer $(\mathrm{KCl} 60 \mathrm{mM}, \mathrm{NaCl} 15 \mathrm{mM}$, Tris $\mathrm{HCl} \mathrm{pH}$ $7.415 \mathrm{mM}$, Saccharose $0.34 \mathrm{M}$, spermidine 0,65 mM, DTT $1 \mathrm{mM}$, Complete Protease Inhibitor Cocktail Tablets Roche EDTA-free, PMSF $1 \mathrm{mM}$, aprotinin $10 \mathrm{mM}$ ) and centrifuged again. Nuclei were resuspended in $200 \mu \mathrm{l}$ of MNase buffer (Tris $\mathrm{HCl} \mathrm{pH7.5} 10 \mathrm{mM}, \mathrm{KCl} 10 \mathrm{mM}, \mathrm{CaCl} 2 \mathrm{mM}$ ) and $5 \mathrm{U}$ of Micrococcal Nuclease (ThermoFisher, Waltham, MA, USA) were added. Samples were immediately incubated in a waterbath at $37^{\circ} \mathrm{C}$ for $10 \mathrm{~min}$. MNase reaction was stopped by adding EDTA to $5 \mathrm{mM}$ final concentration. The nucleosome fraction was isolated by centrifugation at $10000 \mathrm{~g}, 4^{\circ} \mathrm{C}$, for $5 \mathrm{~min}$. ChIP were performed by adding LSDB 250 (glycerol 20\%, Hepes $50 \mathrm{mM}, \mathrm{MgCl} 23 \mathrm{mM}, \mathrm{KCl} 250 \mathrm{mM}$, Complete Protease Inhibitor Cocktail Tablets Roche, PMSF $1 \mathrm{mM}$, Aprotinin $10 \mathrm{mM}$ ) to the nucleosome fraction to a final volume of $500 \mu \mathrm{l}$. Twenty microliter of this suspension were kept as input and immediately frozen at $-20^{\circ} \mathrm{C}$ and the remaining volume was incubated on a rotating wheel at $4{ }^{\circ} \mathrm{C}$ overnight with the beads (Dynabeads protein $\mathrm{G}$, Life technologies) previously coupled with $5 \mu \mathrm{l}$ of anti-H2A.B3). ${ }^{27}$ Samples were processed as described above. Experiments were repeated twice on independent pools of elutriated round spermatids (each representing 2-3 mice) and gave similar results.

ChIP of chromatin marks on elongating/condensing spermatids. Elongating/condensing spermatids were collected by centrifugal elutriation. Aliquots of about $1 \times 10^{7}$ elongating/condensing spermatids were used for chromatin preparation as described previously by Montellier et al. ${ }^{11}$ with some modifications. Briefly, aliquots were suspended in $75 \mu \mathrm{l}$ of lysis Buffer (Tris pH $7.450 \mathrm{mM}, \mathrm{NaCl}$ 300 mM, NP-40 0.1\%, DOC 0.1\%, DTT 1 mM, Complete Protease Inhibitor Cocktail Tablets EDTA-free Roche, PMSF $1 \mathrm{mM}$, aprotinin $10 \mathrm{mM}$, sodium butyrate $5 \mathrm{mM}$ ) for $15 \mathrm{~min}$ on ice with gentle shaking every $3 \mathrm{~min}$. Spermatids were centrifuged at $10000 \mathrm{~g}$ at $4{ }^{\circ} \mathrm{C}$ for $10 \mathrm{~min}$. Supernatant was kept on ice and the pellet was resuspended in $100 \mu \mathrm{l}$ of Lysis buffer and sonicated on PICO-Diagenode for 4 min 
(30 sec ON-30 sec OFF) to allow the suspension of larger chromatin fragment. Spermatids were centrifuged again at $10000 \mathrm{~g}$ at $4{ }^{\circ} \mathrm{C}$ for $10 \mathrm{~min}$ and supernatant was pooled with the first supernatant for MNase digestion. Seventy-five microliter of MNase Buffer (Tris, pH $7.510 \mathrm{mM}, \mathrm{KCl} 10 \mathrm{mM}$, and $\mathrm{CaCl} 21 \mathrm{mM}$ ) were added and MNase digestion was performed by adding $10 \mathrm{U}$ of MNase. Digestion was performed for exactly $10 \mathrm{~min}$ in a waterbath at $37^{\circ} \mathrm{C}$. Digestion was stopped by adding $5 \mathrm{mM}$ EDTA. Five microliter were kept to check MNase digestion on Agilent's 2100 Bioanalyzer. The remaining volume was diluted with Lysis buffer and $20 \mu$ were kept as input. The remaining volume was incubated on a rotating wheel, $4^{\circ} \mathrm{C}$ overnight with magnetic beads (Dynabeads Protein $\mathrm{G}$, Life technologies) previously coupled with the appropriate antibody $(5 \mu \mathrm{l}$ of anti-H3K79me2 (ab-3594 from Abcam, Cambridge, UK), or $9 \mu \mathrm{l}$ of anti-H4panAcetyl antibody (06-866 from Millipore, Billerica, MA, USA)). IP and input were further processed as described above. Experiments were repeated three to four times on independent pools of elutriated elongating/condensing spermatids (each representing 2-3 mice). T-test was used for statistical analyses.

Real-time quantitative PCR. Real-time PCR was performed using Roche LightCycler 480 and SYBRgreen Mastermix (Roche). ChIP-qPCR were performed on purified round spermatids or on elongating/condensing spermatids obtained by elutriation. Each sample represents a pool of 2-3 animals. Primers were designed to amplify regions across the TSS of indicated genes, except for NC which represents a negative control region (used to normalize) located $170 \mathrm{~kb}$ away from any TSS. The sequences and qPCR condition of Akap4 and Actrt1 ChIP primers can be found in Soboleva et $a l^{27}$ for other primers see Supplementary Figure 11.

RT-qPCR were performed on RNA extracted from WT and Sly-KD elutriated round spermatids and reversed-transcribed as described in Cocquet et al. ${ }^{15}$ using primers listed in Supplementary Figure 11. The sequences and qPCR condition of Jmjd1c primers can be found in Kuroki et al., ${ }^{66}$ of $\beta$-actin primers in Cocquet et al., ${ }^{15}$ of Dot 11 H9LAN primers in Dottermusch-Heidel et al., ${ }^{32}$ of $H 2$ afb3 primers in Soboleva et al., ${ }^{27}$ of H2al1, H2al2y and H2afb1 (aka H2al2) primers in Ellis et al. ${ }^{67}$ For the quantification of Flag-Sly transgene expression, RT-qPCR was performed on whole testes as described in Cocquet et al. ${ }^{15}$ using Sly global primers (which amplify Sly1 and other Sly isoforms), Sly1 primers and Acrv1 primers. ${ }^{15,16}$ Student's t-test was used for all qPCR statistical analyses.

Immunofluorescence. Immunofluorescence on sections and on surfacespread testicular cells were performed as previously described. ${ }^{15,65}$ Antibody against DOT1L (ab-64077 from Abcam), H3K79me2 (ab-3594 from Abcam) or AcH4 (06-866 from Millipore) were diluted 1/100 to $1 / 200$. Pictures were taken with an Olympus BX63 microscope. Quantification was performed on pictures obtained from six samples per genotype using ImageJ 1.48v (http://imagej.nih.gov/ij/). T-tests were performed with GraphPad Prism 5.02.

Quantification of DNA oxidation. Detection of 8-hydroxy-2'-deoxyguanosine (8-oxo-dG) was carried out on spermatozoa from cauda epididymis. Spermatozoa were resuspended in a decondensing buffer consisting of $2 \mathrm{mM}$ DTT and $0.5 \%$ Triton X-100 in PBS $1 \times$ and incubated for $30 \mathrm{~min}$ at room temperature. After centrifugation at $800 \mathrm{~g}$ for $5 \mathrm{~min}$ at room temperature, spermatozoa were washed in $1 \times$ PBS and smeared on a glass plate ( 250000 cells/plate). The 8-oxo$\mathrm{dG}$ immunostaining were performed as previously described by Noblanc et al. ${ }^{68}$ using a monoclonal antibody against 8-oxo-dG (15A3, Novus biological, Interchim, France). To evaluate the percentage of spermatozoa with 8-oxo-dG staining, 300 spermatozoa per sample were scored, and 5-7 samples per genotype were analyzed. A positive control consisting in pre-treating spermatozoa with $\mathrm{H} 202$ was included in the analysis $(n=3)$. Mann-Whitney nonparametric tests were performed using GraphPad Prism 5.02.

Transfection and protein extraction of GC1 cells. The open reading frames of Sly $1^{16}$ was cloned in-frame with an N-terminal FLAG tag under the control of the CMV promoter of the pCDNA3.1 vector (Invitrogen, Carlsbad, CA, USA). GC1-spg cells were transfected using Lipofectamine 2000 (Invitrogen) according to the manufacturer's instructions with pCDNA3.1-CMV-FLAG-SLY vector (i.e., FLAG SLY) and pCDNA3.1 empty vector. Cells were collected for protein extraction $24 \mathrm{~h}$ after transfection and pelleted by centrifugation for $5 \mathrm{~min}$ at $1000 \mathrm{~g}$. Proteins were extracted using ice-cold lysis buffer $(150 \mathrm{mM} \mathrm{NaCl}, 20 \mathrm{mM}$ Tris/ $/ \mathrm{HCl}$ pH 8.0, $5 \mathrm{mM}$ EDTA, 0.5\% Igepal CA-630 (Sigma-aldrich), $1 \mathrm{mM}$ phenylmethanesulfonyl fluoride, $1 \mathrm{mM}$ sodium orthovanadate and $1 \times$ Complete, Mini, EDTA-free Protease Inhibitor Cocktail) at $4{ }^{\circ} \mathrm{C}$ for $30 \mathrm{~min}$ on a rotating platform. After centrifugation at $13000 \mathrm{~g}$ at $4^{\circ} \mathrm{C}$ for $5 \mathrm{~min}$, the supernatant was collected and immediately used for the in vitro immunoprecipitation assay and mass spectrometry analysis.

Protein extraction from testes. Nuclear and cytosolic fractions were obtained from adult testes as described in Cocquet et al. ${ }^{33}$ Protein extraction prior to immunoprecipitation was performed as follow: flash-frozen testes were ground and resuspended in 1: 9 w/v ice-cold extraction buffer ( $150 \mathrm{mM} \mathrm{NaCl}, 20 \mathrm{mM}$ Tris/

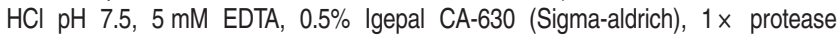
inhibitor cocktail (Sigma-Aldrich), $1 \mathrm{mM}$ phenylmethanesulfonyl fluoride and $1 \mathrm{mM}$ sodium orthovanade). After homogenization and incubation at $4{ }^{\circ} \mathrm{C}$ for $30 \mathrm{~min}$, tissue lysates were centrifuged at $13000 \mathrm{~g}$ at $4^{\circ} \mathrm{C}$ for $10 \mathrm{~min}$. The supernatant was collected and immediately used for the immunoprecipitation assays.

Co-immunoprecipitation. For immunoprecipitation assays in GC1 cells, $60 \mu \mathrm{l}$ of anti-FLAG M2 magnetic beads (Sigma-aldrich) were washed three times in $1 \times$ TBS (150 mM NaCl, $50 \mathrm{mM}$ Tris, pH 7.4) and incubated with $600 \mu$ l of protein extract from transiently transfected cells for $2 \mathrm{~h}$ at $4{ }^{\circ} \mathrm{C}$. The magnetic beads were then washed two times in $500 \mu \mathrm{l}$ of TBS with $0.5 \%$ Tween-20 and then incubated for a long wash for $5 \mathrm{~min}$ at room temperature in TBS only. For non-denaturing elution, beads were resuspended in $150 \mu$ l elution buffer $(0.1 \mathrm{M}$ glycine/ $\mathrm{HCl}, \mathrm{pH} 3.0)$, and incubated at room temperature for $5 \mathrm{~min}$. The $\mathrm{pH}$ was neutralized using triethylammonium bicarbonate buffer ( $\mathrm{pH}$ 8.4).

For immunoprecipitation assays in whole-testicular extracts, $40 \mu \mathrm{l}$ of BioAdembeads PAG (Ademtech, Pessac, France) or were washed two times in $80 \mu \mathrm{l}$ of PBS $0.65 \%$ Tween 20 and resuspended with $4 \mu \mathrm{g}$ of anti-SLY antibody, antiTBLX1R1 antibody (ab 24550, Abcam) and purified rabbit IgG (02-6102, Invitrogen) for $30 \mathrm{~min}$ at room temperature to allow binding of the antibody. Beads were washed two times in PBS $0.65 \%$ Tween 20, incubated with $200 \mu \mathrm{l}$ of $20 \mathrm{mM}$ of dimethylpimelimidate to covalently coupled the antibodies to the beads for $30 \mathrm{~min}$ at room temperature and the reaction was stopped by resuspended the beads with $40 \mu \mathrm{l}$ of $50 \mathrm{mM}$ Tris pH 7.5 for $15 \mathrm{~min}$. Bio-Adembeads PAG beads and $40 \mu \mathrm{l}$ of antiFLAG M2 magnetic beads (Sigma-aldrich) were incubated with $400 \mu$ l of protein extract for $2 \mathrm{~h}$ at $4{ }^{\circ} \mathrm{C}$, and washed two times in PBS $0.65 \%$ Tween 20 and then incubated for a long wash for $5 \mathrm{~min}$ in PBS only. For non-denaturing elution, BioAdembeads PAG beads were resuspended in $30 \mu \mathrm{l}$ elution buffer and anti-FLAG M2 magnetic beads were resuspended in $100 \mu$ l elution buffer, and incubated at room temperature for $5 \mathrm{~min}$. The $\mathrm{pH}$ was neutralized using triethylammonium bicarbonate buffer ( $\mathrm{pH}$ 8.4).

Alternatively, Dynabeads Protein $\mathrm{G}$ (Life technologies) were used as instructed by the manufacturer and resuspended in $800 \mu \mathrm{l}$ binding buffer with anti-SLY antibody or purified rabbit IgG (Life technologies), and incubated overnight at $4{ }^{\circ} \mathrm{C}$ to allow

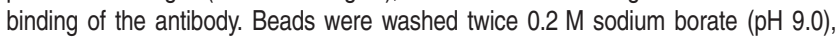
incubated in $30 \mathrm{mM}$ dimethylpimelimidate for $30 \mathrm{~min}$ at room temperature to covalently couple the antibodies to the beads, washed three times in $0.2 \mathrm{M}$ ethanolamine ( $\mathrm{pH} 8.0$ ), and then washed twice in $1 \mathrm{ml}$ binding buffer. Antibodycoupled beads were incubated with whole-testis extracts for $1 \mathrm{~h}$, and washed three times in extraction buffer and once in $1 \times$ TBS with $0.05 \%$ Triton X-100 for 5 min. Elution was performed using $0.1 \mathrm{M}$ glycine/ $/ \mathrm{HCl}, \mathrm{pH} 3.0$. The $\mathrm{pH}$ was neutralized using triethylammonium bicarbonate buffer ( $\mathrm{pH} 8.4$ ).

Western blot. Protein extraction and western blot experiments on whole testes and elutriated spermatids were performed as described in Comptour et al..$^{65}$ In brief, $15 \mu \mathrm{l}$ of each immunoprecipitated sample and a volume of input sample corresponding to $10 \%$ of IP sample were denatured using $4 \times$ NuPAGE LDS sample buffer (Life Technologies) with 10\% $\beta$-mercaptoethanol, boiled for 10 min at $95{ }^{\circ} \mathrm{C}$ and loaded. Extraction of sperm proteins was as follow: five millions of spermatozoa (purity $\geqslant 99 \%$ ) were resuspended in $200 \mu \mathrm{l}$ of $4 \times$ NuPAGE LDS sample buffer (Life Technologies) and boiled for $10 \mathrm{~min}$ at $95^{\circ} \mathrm{C}$. Ten microliter of sample were loaded per lane. Antibody against $S L Y^{14}$ was diluted $1 / 3000$, antibody against SLX/SLXL1, 69 1/6000, anti-H3K79me2 (ab-3594 from Abcam), antiTBLX1R1 (ab 24550 from Abcam), anti-Tubulin antibody (T-9026 from Sigma-Aldrich), anti-panH3 antibody (05-928 from Abcam), anti-FLAG (M5 from Sigma-Aldrich) and anti-Hup2B antibody (Briar Patch Biosciences, Grass Valley, CA, USA), $1 / 1000$.

Sample digestion and LC-MS/MS. Co-immunoprecipitated samples were subjected to a bottom-up analysis at the 3P5 university platform. After, cysteines reduction with dithiothreitol and alkylation with chloroacetamide, proteins were 
digested using trypsin and analyzed by LC-MS/MS using method described in Lahouassa et al. ${ }^{70}$

Spectra processing, peptide identification. The software Proteome discoverer 1.3 was used to generate.mgf files. The threshold of signal to noise for extraction values was 3. MS/MS spectra were submitted to MASCOT version 2.5.1 and Maxquant version 1.5.2.8. The database used was a concatenation of Mouse sequence of $\mathrm{NCBI}$ database. Oxidation of methionine was permitted partially, whereas carbamidomethylation of cysteine was considered complete. LFQ option without match between runs was used in Maxquant. Two anti-FLAG co-immunoprecipitation assays were performed respectively on whole testis and on transiently transfected GC1 cells. For whole-testis experiment, duplicate mass spectrometry analyses were performed and were independently analyzed with MASCOT; Table 3 shows the results of MASCOT analysis of the second experiment. The results of the two duplicate experiments were pooled for Maxquant analysis. In MASCOT analyses, the protein score is the sum of the highest MS/MS ions score for each distinct peptide sequence. So the highest the protein score, the more it is represented in the sample. However, for an identical mole of protein, a larger protein can give more peptides than a smaller one. EmPAI (Exponentially Modified Protein Abundance Index) value provides a complementary information as it depends on the number of detected peptides compared to the total number of detectable peptides. The higher the EmPAl, the more abundant the protein. In Table 3, only Maxquant LFQ is more accurate than EmPAI because it reflects the total LC-MS intensity of peptides for the proteins.

\section{Conflict of Interest}

The authors declare no conflict of interest.

Acknowledgements. We thank Monika Ward for helpful discussions, Aine Rattigan and Anne-Marie Lachages for help with elutriation settings, Sophie Wood and other members of the NIMR transgenesis facility for pronuclear injections. We also thank Matthieu Benard and other staff members of the Cochin Institute Mouse House Facility, Antoine Gueraud for DNA extraction, Franck Letourneur, Florent Dumont and Juliana Pipoli from the Genomic Facility, Evangeline Bennana and François Guillonneau from the 3P5 proteomic facility, as well as the Histology, Immunostaining and Laser Microdissection Facility, the Cellular Imaging Facility and the Cytometry and Immunobiology Facility of the Cochin Institute (INSERM U1016, CNRS UMR8104, Université Paris Descartes). This work was supported by Inserm (Institut National de la Sante et de la Recherche Medicale), the Agence Nationale de la Recherche program ANR-12-JSV2-0005-01 (to JC), Labex 'Who am I?'(ANR-11LABX-0071 under program ANR-11-IDEX-0005-01) and a Marie Curie fellowship FP7-PEOPLE-2010-IEF-273143 (to JC).

1. Yan W. Male infertility caused by spermiogenic defects: lessons from gene knockouts. Mol Cell Endocrinol 2009; 306: 24-32.

2. White-Cooper $\mathrm{H}$, Davidson I. Unique aspects of transcription regulation in male germ cells. Cold Spring Harb Perspect Biol 2011; 3: a002626.

3. Schultz N, Hamra FK, Garbers DL. A multitude of genes expressed solely in meiotic or postmeiotic spermatogenic cells offers a myriad of contraceptive targets. Proc Natl Acad Sci USA 2003; 100: 12201-12206.

4. Shima JE, McLean DJ, McCarrey JR, Griswold MD. The murine testicular transcriptome: characterizing gene expression in the testis during the progression of spermatogenesis. Biol Reprod 2004; 71: 319-330.

5. Chalmel F, Rolland AD, Niederhauser-Wiederkehr C, Chung SS, Demougin P, Gattiker A et al. The conserved transcriptome in human and rodent male gametogenesis. Proc Natl Acad Sci USA 2007; 104: 8346-8351.

6. Soumillon M, Necsulea A, Weier M, Brawand D, Zhang X, Gu H et al. Cellular source and mechanisms of high transcriptome complexity in the mammalian testis. Cell Rep 2013; 3: 2179-2190.

7. Rathke C, Baarends WM, Awe S, Renkawitz-Pohl R. Chromatin dynamics during spermiogenesis. Biochim Biophys Acta 2014; 1839: 155-168.

8. Cho C, Willis WD, Goulding EH, Jung-Ha H, Choi YC, Hecht NB et al. Haploinsufficiency of protamine-1 or -2 causes infertility in mice. Nat Genet 2001; 28: 82-86.

9. Cho $\mathrm{C}$, Jung-Ha H, Willis WD, Goulding EH, Stein $\mathrm{P}, \mathrm{Xu} Z \mathrm{Z}$ et al. Protamine 2 deficiency leads to sperm DNA damage and embryo death in mice. Biol Reprod 2003; 69: 211-217.

10. Gaucher J, Boussouar F, Montellier E, Curtet S, Buchou T, Bertrand S et al. Bromodomaindependent stage-specific male genome programming by Brdt. EMBO $J$ 2012; 31: 3809-3820.
11. Montellier E, Boussouar F, Rousseaux S, Zhang K, Buchou T, Fenaille F et al. Chromatin-tonucleoprotamine transition is controlled by the histone H2B variant TH2B. Genes Dev 2013; 27: 1680-1692.

12. Li W, Wu J, Kim SY, Zhao M, Hearn SA, Zhang MQ et al. Chd5 orchestrates chromatin remodelling during sperm development. Nat Commun 2014; 5: 3812.

13. Yamauchi $Y$, Riel JM, Stoytcheva Z, Burgoyne PS, Ward MA. Deficiency in mouse $Y$ chromosome long arm gene complement is associated with sperm DNA damage. Genome Biol 2010; 11: R66.

14. Reynard LN, Cocquet J, Burgoyne PS. The multi-copy mouse gene Sycp3-like Y-linked (Sly) encodes an abundant spermatid protein that interacts with a histone acetyltransferase and an acrosomal protein. Biol Reprod 2009; 81: 250-257.

15. Cocquet J, Ellis PJ, Yamauchi Y, Mahadevaiah SK, Affara NA, Ward MA et al. The multicopy gene Sly represses the sex chromosomes in the male mouse germline after meiosis. PLOS Biol 2009; 7: e1000244.

16. Riel JM, Yamauchi Y, Sugawara A, Li HY, Ruthig V, Stoytcheva Z et al. Deficiency of the multi-copy mouse $Y$ gene Sly causes sperm DNA damage and abnormal chromatin packaging. J Cell Sci 2013; 126: 803-813.

17. Yuan L, Liu J-G, Zhao J, Brundell E, Daneholt B, Höög C. The murine SCP3 gene is required for synaptonemal complex assembly, chromosome synapsis, and male fertility. Mol Cell 2000; 5: 73-83.

18. Gan H, Wen L, Liao S, Lin X, Ma T, Liu J et al. Dynamics of 5-hydroxymethylcytosine during mouse spermatogenesis. Nat Commun 2013; 4: 1995

19. Bryant JM, Donahue G, Wang X, Meyer-Ficca M, Luense LJ, Weller AH et al. Characterization of BRD4 during mammalian postmeiotic sperm development. $\mathrm{Mol}$ Cell Biol 2015; 35: 1433-1448.

20. Erkek S, Hisano M, Liang CY, Gill M, Murr R, Dieker J et al. Molecular determinants of nucleosome retention at $\mathrm{CpG}$-rich sequences in mouse spermatozoa. Nat Struct Mol Biol 2013; 20: 868-875.

21. Tan M, Luo H, Lee S, Jin F, Yang JS, Montellier E et al. Identification of 67 histone marks and histone lysine crotonylation as a new type of histone modification. Cell 2011; 146: 1016-1028.

22. Hammoud SS, Low DH, Yi C, Carrell DT, Guccione E, Cairns BR. Chromatin and transcription transitions of mammalian adult germline stem cells and spermatogenesis. Cell Stem Cell 2014; 15: 239-253

23. Bernstein BE, Kamal M, Lindblad-Toh K, Bekiranov S, Bailey DK, Huebert DJ et al. Genomic maps and comparative analysis of histone modifications in human and mouse. Cell 2005 120: $169-181$.

24. Creyghton MP, Cheng AW, Welstead GG, Kooistra T, Carey BW, Steine EJ et al. Histone H3K27ac separates active from poised enhancers and predicts developmental state. Proc Natl Acad Sci USA 2010; 107: 21931-21936.

25. Benayoun BA, Pollina EA, Ucar D, Mahmoudi S, Karra K, Wong ED et al. H3K4me3 breadth is linked to cell identity and transcriptional consistency. Cell 2014; 158: 673-688.

26. Wong ML, Medrano JF. Real-time PCR for mRNA quantitation. Biotechniques 2005; 39 : 75-85.

27. Soboleva TA, Nekrasov M, Pahwa A, Williams R, Huttley GA, Tremethick DJ. A unique H2A histone variant occupies the transcriptional start site of active genes. Nat Struct Mol Biol 2011; 19: 25-30

28. Govin J, Escoffier E, Rousseaux S, Kuhn L, Ferro M, Thevenon J et al. Pericentric heterochromatin reprogramming by new histone variants during mouse spermiogenesis. J Cell Biol 2007; 176: 283-294.

29. Ferguson L, Ellis PJ, Affara NA. Two novel mouse genes mapped to chromosome Yp are expressed specifically in spermatids. Mamm Genome 2009; 20: 193-206.

30. Martianov I, Brancorsini S, Catena R, Gansmuller A, Kotaja N, Parvinen M et al. Polar nuclear localization of $\mathrm{H} 1 \mathrm{~T} 2$, a histone $\mathrm{H} 1$ variant, required for spermatid elongation and DNA condensation during spermiogenesis. Proc Natl Acad Sci USA 2005; 102: 2808-2813.

31. Dottermusch-Heidel C, Gartner SM, Tegeder I, Rathke C, Barckmann B, Bartkuhn M et al. H3K79 methylation: a new conserved mark that accompanies $\mathrm{H} 4$ hyperacetylation prior to histone-to-protamine transition in Drosophila and rat. Biol Open 2014; 3: 444-452.

32. Dottermusch-Heidel C, Klaus ES, Gonzalez NH, Bhushan S, Meinhardt A, Bergmann M et al. H3K79 methylation directly precedes the histone-to-protamine transition in mammalian spermatids and is sensitive to bacterial infections. Andrology 2014; 2: 655-665.

33. Cocquet J, Ellis PJ, Mahadevaiah SK, Affara NA, Vaiman D, Burgoyne PS. A genetic basis for a postmeiotic $X$ versus $Y$ chromosome intragenomic conflict in the mouse. PLOS Genet 2012; 8: e1002900.

34. Gilan O, Lam EY, Becher I, Lugo D, Cannizzaro E, Joberty G et al. Functional interdependence of BRD4 and DOT1L in MLL leukemia. Nat Struct Mol Biol 2016; 23: 673-681.

35. Brykczynska U, Hisano M, Erkek S, Ramos L, Oakeley EJ, Roloff TC et al. Repressive and active histone methylation mark distinct promoters in human and mouse spermatozoa. Nat Struct Mol Biol 2010; 17: 679-687.

36. Chabory E, Damon C, Lenoir A, Kauselmann G, Kern H, Zevnik B et al. Epididymis seleno-independent glutathione peroxidase 5 maintains sperm DNA integrity in mice. $J$ Clin Invest 2009; 119: 2074-2085.

37. Sin HS, Kartashov AV, Hasegawa K, Barski A, Namekawa SH. Poised chromatin and bivalent domains facilitate the mitosis-to-meiosis transition in the male germline. BMC Bio 2015; 13: 53.

38. Moretti C, Vaiman D, Tores F, Cocquet J. Expression and epigenomic landscape of the sex chromosomes in mouse post-meiotic male germ cells. Epigenetics Chromatin 2016; 9: 47. 
39. Syrjanen JL, Pellegrini L, Davies OR. A molecular model for the role of SYCP3 in meiotic chromosome organisation. Elife 2014: 3: e02963.

40. Li J, Wang J, Wang J, Nawaz Z, Liu JM, Qin J et al. Both corepressor proteins SMRT and $\mathrm{N}-\mathrm{CoR}$ exist in large protein complexes containing HDAC3. EMBO J 2000; 19: $4342-4350$.

41. Zhang J, Kalkum M, Chait BT, Roeder RG. The N-CoR-HDAC3 nuclear receptor corepressor complex inhibits the JNK pathway through the integral subunit GPS2. Mol Cell 2002; 9: 611-623.

42. Yoon HG, Chan DW, Reynolds AB, Qin J, Wong J. N-CoR mediates DNA methylationdependent repression through a methyl CpG binding protein Kaiso. Mol Cell 2003; 12: 723-734.

43. Zhang D, Yoon HG, Wong J. JMJD2A is a novel N-CoR-interacting protein and is involved in repression of the human transcription factor achaete scute-like homologue 2 (ASCL2) Hash2). Mol Cell Biol 2005; 25: 6404-6414.

44. Perissi V, Scafoglio C, Zhang J, Ohgi KA, Rose DW, Glass CK et al. TBL1 and TBLR1 phosphorylation on regulated gene promoters overcomes dual CtBP and NCoR/SMRT transcriptional repression checkpoints. Mol Cell 2008; 29: 755-766.

45. Perissi V, Jepsen K, Glass CK, Rosenfeld MG. Deconstructing repression: evolving models of co-repressor action. Nat Rev Genet 2010; 11: 109-123.

46. Ellis PJ, Bacon J, Affara NA. Association of Sly with sex-linked gene amplification during mouse evolution: a side effect of genomic conflict in spermatids? Hum Mol Genet 2011; 20: 3010-3021.

47. Soh YQ, Alfoldi J, Pyntikova T, Brown LG, Graves T, Minx PJ et al. Sequencing the mouse $Y$ chromosome reveals convergent gene acquisition and amplification on both sex chromosomes. Cell 2014; 159: 800-813.

48. Helleu Q, Gerard PR, Montchamp-Moreau C. Sex chromosome drive. Cold Spring Harb Perspect Biol 2014; 7: a017616.

49. Feng $\mathrm{Q}$, Wang $\mathrm{H}, \mathrm{Ng} \mathrm{HH}$, Erdjument-Bromage $\mathrm{H}$, Tempst $\mathrm{P}$, Struhl $\mathrm{K}$ et al. Methylation of H3-lysine 79 is mediated by a new family of HMTases without a SET domain. Curr Biol 2002 ; 12: $1052-1058$.

50. Zhang $\mathrm{W}$, Hayashizaki $\mathrm{Y}$, Kone $\mathrm{BC}$. Structure and regulation of the mDot1 gene, a mouse histone $\mathrm{H3}$ methyltransferase. Biochem J 2004; 377: 641-651.

51. Ontoso D, Kauppi L, Keeney S, San-Segundo PA. Dynamics of DOT1L localization and H3K79 methylation during meiotic prophase I in mouse spermatocytes. Chromosoma 2014; 123: $147-164$.

52. Devaiah BN, Case-Borden C, Gegonne A, Hsu CH, Chen Q, Meerzaman D et al. BRD4 is a histone acetyltransferase that evicts nucleosomes from chromatin. Nat Struct Mol Biol 2016; 23: $540-548$.

53. Lord T, Aitken RJ. Fertilization stimulates 8-hydroxy-2'-deoxyguanosine repair and antioxidant activity to prevent mutagenesis in the embryo. Dev Biol 2015; 406: 1-13.

54. Aitken RJ, Smith TB, Jobling MS, Baker MA, De luliis GN. Oxidative stress and male reproductive health. Asian J Androl 2014; 16: 31-38

55. Li H, Durbin R. Fast and accurate long-read alignment with Burrows-Wheeler transform. Bioinformatics 2010; 26: 589-595.

56. Li H, Handsaker B, Wysoker A, Fennell T, Ruan J, Homer N et al. The Sequence Alignment Map format and SAMtools. Bioinformatics 2009; 25: 2078-2079.

57. Zhang Y, Liu T, Meyer CA, Eeckhoute J, Johnson DS, Bernstein BE et al. Model-based analysis of ChIP-Seq (MACS). Genome Biol 2008; 9: R137.

58. Ramirez F, Dundar F, Diehl S, Gruning BA, Manke T. deepTools: a flexible platform for exploring deep-sequencing data. Nucleic Acids Res 2014; 42: W187-W191.

59. Subramanian A, Tamayo P, Mootha VK, Mukherjee S, Ebert BL, Gillette MA et al. Gene set enrichment analysis: a knowledge-based approach for interpreting genome-wide expression profiles. Proc Natl Acad Sci USA 2005; 102: 15545-15550.
60. Chen EY, Tan CM, Kou Y, Duan Q, Wang Z, Meirelles GV et al. Enrichr: interactive and collaborative HTML5 gene list enrichment analysis tool. BMC Bioinformatics 2013; 14: 128.

61. Spiess AN, Feig C, Schulze W, Chalmel F, Cappallo-Obermann H, Primig M et al. Cross-platform gene expression signature of human spermatogenic failure reveals inflammatory-like response. Hum Reprod 2007; 22: 2936-2946.

62. Reddi PP, Flickinger CJ, Herr JC. Round spermatid-specific transcription of the mouse SP-10 gene is mediated by a 294-base pair proximal promoter. Biol Reprod 1999; 61: $1256-1266$.

63. Reddi PP, Shore AN, Shapiro JA, Anderson A, Stoler MH, Acharya KK. Spermatid-specific promoter of the SP-10 gene functions as an insulator in somatic cells. Dev Biol 2003; 262: 173-182.

64. Bastos H, Lassalle B, Chicheportiche A, Riou L, Testart J, Allemand I et al. Flow cytometric characterization of viable meiotic and postmeiotic cells by Hoechst 33342 in mouse spermatogenesis. Cytometry A 2005; 65: 40-49.

65. Comptour A, Moretti C, Serrentino ME, Auer J, laly-Radio C, Ward MA et al. SSTY proteins co-localize with the post-meiotic sex chromatin and interact with regulators of its expression. FEBS J 2014; 281: 1571-1584.

66. Kuroki S, Akiyoshi M, Tokura M, Miyachi H, Nakai Y, Kimura H et al. JMJD1C, a JmjC domain-containing protein, is required for long-term maintenance of male germ cells in mice. Biol Reprod 2013; 89: 93

67. Ellis PJI, Clemente EJ, Ball P, Toure A, Ferguson L, Turner JMA et al. Deletions on mouse Yq lead to upregulation of multiple X- and Y-linked transcripts in spermatids. Hum Mol Genet 2005; 14: 2705-2715

68. Noblanc A, Damon-Soubeyrand C, Karrich B, Henry-Berger J, Cadet R, Saez F et al. DNA oxidative damage in mammalian spermatozoa: where and why is the male nucleus affected? Free Radic Biol Med 2013; 65: 719-723.

69. Reynard LN, Turner JM, Cocquet J, Mahadevaiah SK, Toure A, Hoog C et al. Expression analysis of the mouse multi-copy X-linked gene XIr-related, meiosis-regulated (Xmr), reveals that Xmr encodes a spermatid-expressed cytoplasmic protein, SLX/XMR. Biol Reprod 2007; 77: $329-335$

70. Lahouassa H, Blondot ML, Chauveau L, Chougui G, Morel M, Leduc M et al. HIV-1 Vpr degrades the HLTF DNA translocase in T cells and macrophages. Proc Natl Acad Sci USA 2016; 113: 5311-5316.

71. Montellier E, Rousseaux S, Zhao Y, Khochbin S. Histone crotonylation specifically marks the haploid male germ cell gene expression program: post-meiotic male-specific gene expression. BioEssays 2012; 34: 187-193.

(c) (i) (a) (2) This work is licensed under a Creative Commons Attribution-NonCommercial-ShareAlike 4.0 International License. The images or other third party material in this article are included in the article's Creative Commons license, unless indicated otherwise in the credit line; if the material is not included under the Creative Commons license, users will need to obtain permission from the license holder to reproduce the material. To view a copy of this license, visit http://creativecommons.org/licenses/by-nc-sa/4.0/

(C) The Author(s) 2017

Supplementary Information accompanies this paper on Cell Death and Differentiation website (http://www.nature.com/cdd) 